Atmos. Chem. Phys., 10, 2439-2456, 2010

www.atmos-chem-phys.net/10/2439/2010/

(C) Author(s) 2010. This work is distributed under

the Creative Commons Attribution 3.0 License.

\title{
Iodine monoxide in the Antarctic snowpack
}

\author{
U. Frieß ${ }^{1}$, T. Deutschmann ${ }^{1}$, B. S. Gilfedder ${ }^{2}$, R. Weller ${ }^{3}$, and U. Platt ${ }^{1}$ \\ ${ }^{1}$ Institute of Environmental Physics, University of Heidelberg, Heidelberg, Germany \\ ${ }^{2}$ Institut für Umweltgeologie, TU-Braunschweig, Germany \\ ${ }^{3}$ Alfred Wegener Institut für Polar- und Meeresforschung, Bremerhaven, Germany
}

Received: 9 November 2009 - Published in Atmos. Chem. Phys. Discuss.: 26 November 2009

Revised: 26 February 2010 - Accepted: 3 March 2010 - Published: 11 March 2010

\begin{abstract}
Recent ground-based and space borne observations suggest the presence of significant amounts of iodine monoxide in the boundary layer of Antarctica, which are expected to have an impact on the ozone budget and might contribute to the formation of new airborne particles. So far, the source of these iodine radicals has been unknown. This paper presents long-term measurements of iodine monoxide at the German Antarctic research station Neumayer, which indicate that high IO concentrations in the order of $50 \mathrm{ppb}$ are present in the snow interstitial air. The measurements have been performed using multi-axis differential optical absorption spectroscopy (MAX-DOAS). Using a coupled atmosphere - snowpack radiative transfer model, the comparison of the signals observed from scattered skylight and from light reflected by the snowpack yields several ppb of iodine monoxide in the upper layers of the sunlit snowpack throughout the year. Snow pit samples from Neumayer Station contain up to $700 \mathrm{ng} / \mathrm{l}$ of total iodine, representing a sufficient reservoir for these extraordinarily high IO concentrations.
\end{abstract}

\section{Introduction}

It is known since the mid 1980s that a strong enrichment in iodine is present in coastal areas of Antarctica. Evidence came from analysis of meteorites collected on the shelf ice of Antarctica (Dreibus and Wänke, 1983). Extremely high iodine concentrations of $11-15 \mathrm{ppm}$ were measured in Antarctic meteorites, whereas the mean iodine content in

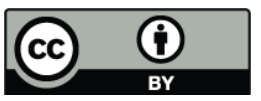

Correspondence to: $\mathrm{U}$. Frieß (udo.friess@iup.uni-heidelberg.de)
non-Antarctic meteorites of the same type was only $0.07 \mathrm{ppm}$ (Dreibus et al., 1979). Later, Heumann et al. (1987) analysed meteorites, rock samples, snow and aerosols near the Antarctic coast. They found more than $1 \mathrm{ppm}$ of iodine in meteorites and $\mathrm{I} / \mathrm{Cl}$ ratios in snow samples 10-190 times higher than in sea water, but no or only small enrichment in chlorine and bromine. Rock samples showed a decrease of the iodine - but not bromine and chlorine - concentration from the surface to the centre of the samples, leading to the conclusion that atmospheric iodine compounds react with surfaces of Antarctic rocks. This finding was confirmed by halogen depth profiles in Antarctic chondrides, which showed an enrichment in iodine at the surface not present in samples anywhere else in the world (Langenauer and Krähenbühl, 1993). Heumann et al. (1987) found an iodine enrichment not only on meteorites, but also in Antarctic snow samples. Since the lifetime of inorganic iodine compounds (e.g., $\mathrm{I}_{2}$ and $\mathrm{HI}$ ) was too short to explain the iodine high abundance off the coast, Heumann et al. (1987) concluded from the lack of iodine enrichment in aerosol samples that iodine must be transported from the coast to inland Antarctica in gaseous form as organoiodides (e.g., methyl iodide with a lifetime of $\approx 5$ days), where it is deposited on the snowpack, meteorites and rocks. However, the exact chemical mechanisms leading to the deposition and strong accumulation of iodine in Antarctica still remains unknown.

A possible mechanism for the release of gaseous iodine compounds from the ocean is the production of molecular iodine $\left(\mathrm{I}_{2}\right)$ and hypoiodus acid (HOI) in the surface seawater by reaction of ambient ozone with iodide (Garland et al., 1980; Thompson and Zafiriou, 1983):

$\mathrm{O}_{3}+\mathrm{I}^{-}+\mathrm{H}_{2} \mathrm{O} \rightarrow \mathrm{HOI}+\mathrm{O}_{2}+\mathrm{OH}^{-}$

Published by Copernicus Publications on behalf of the European Geosciences Union. 
$\mathrm{HOI}+\mathrm{I}^{-}+\mathrm{H}^{+} \rightarrow \mathrm{I}_{2}+\mathrm{H}_{2} \mathrm{O}$

The short-lived compounds $\mathrm{I}_{2}$ and HOI subsequently react with dissolved organic matter in the seawater to produce iodinated organic compounds, such as $\mathrm{CH}_{3} \mathrm{I}, \mathrm{CH}_{2} \mathrm{I}_{2}, \mathrm{CH}_{2} \mathrm{ICl}$, which escape to the atmosphere owing to their high volatility (Martino et al., 2009). In particular methyl iodide $\left(\mathrm{CH}_{3} \mathrm{I}\right)$, with a photochemical lifetime of several days, can be transported inland before it is either deposited on the snow surface or photochemically destroyed to form reactive iodine compounds.

Iodine monoxide (IO) mixing ratios of several ppt have been detected by ground-based passive and active differential optical absorption spectroscopy (DOAS) (Frieß et al., 2001; Saiz-Lopez et al., 2007b). Observations from satellite (Schönhardt et al., 2008; Saiz-Lopez et al., 2007a) indicate that the presence of IO is a widespread phenomenon along the Antarctic coast and over the sea ice covered Antarctic ocean.

The presence of iodine monoxide in the ppt range is expected to have a significant impact on the chemistry of the Antarctic boundary layer. It is expected to cause the destruction of ozone via catalytic cycles involving the reaction of IO with a second halogen oxide molecule (BrO or IO) or with OH (Vogt et al., 1999; McFiggans et al., 2000):

$$
\begin{aligned}
2 \mathrm{I}+2 \mathrm{O}_{3} & \rightarrow 2 \mathrm{IO}+2 \mathrm{O}_{2} \\
\mathrm{IO}+\mathrm{IO} & \rightarrow 2 \mathrm{I}+\mathrm{O}_{2} \\
& \rightarrow \mathrm{OIO}+\mathrm{I} \\
& \rightarrow \mathrm{I}_{2} \mathrm{O}_{2}
\end{aligned}
$$

Reactions (R3) and (R4), as well as possible interhalogen reactions (i.e., IO+BrO) (Solomon et al., 1994; Vogt et al., 1999; Saiz-Lopez et al., 2007a), lead to the catalytic destruction of ozone. The branching ratio of OIO formation via IO self Reaction (R5) is $\approx 40 \%$ (Bloss et al., 2001). Estimates of the OIO lifetime range from several seconds to about one minute (Cox et al., 1999; Tucceri et al., 2006). However, recent laboratory studies indicate that the quantum yield for photolysis of OIO is close to unity (Gómez Martín et al., 2009), leading to very short photochemical lifetimes. The production of higher iodine oxides by polymerisation of OIO molecules possibly leads to the formation of new particles which may act as aerosol condensation nuclei (O'Dowd and Hoffmann, 2006) and might represent a sink for reactive iodine. $\mathrm{I}_{2} \mathrm{O}_{2}$ is unstable and probably decays to regenerate IO.

Apart from some indications for small amounts of tropospheric IO in Spitsbergen by Wittrock et al. (2000), IO has not been detected in the Arctic. It is yet unknown why this hemispheric asymmetry exists and what the sources for the elevated levels of reactive iodine in Antarctica are. The emission of organoiodides (i.e., $\mathrm{CH}_{3} \mathrm{I}, \mathrm{CH}_{2} \mathrm{I}_{2}$ ) by macroalgae and the subsequent photodegradation of these compounds with photochemical lifetimes ranging between seconds and days has been identified as a source of reactive iodine in coastal areas of the mid latitudes (Alicke et al., 1999; Carpenter et al., 1999; Allan et al., 2000). However, these measurements were performed directly at algae fields in intertidal areas, suggesting that the emission of short-lived organic iodine compounds (e.g., $\mathrm{CH}_{2} \mathrm{I}_{2}$ with a lifetime of only several minutes), or the direct emission of molecular iodine from seaweed represents the main source for reactive iodine (Carpenter, 2003). In contrast, the presence of high amounts of iodine in Antarctica, both deposited on the surface and detected in reactive form from satellite far inland, suggests that long-range transport of iodine occurs via methyl iodide with a lifetime of several days.

This paper presents long-term measurements of IO by Multi-Axis DOAS in the Antarctic coastal region, performed at the German research station Neumayer II. By pointing the telescope not only upwards to the sky but also downwards on the snow surface, additional information on the trace gas distribution below the instrument and in the snowpack can be gained. The variation of the IO signal with elevation angle can only be explained by large IO amounts in the snow interstitial air, with mixing ratios of several ppb. Total iodine measurements in snowpit samples from Neumayer indicate that particulate iodine accumulated during winter is released to the gas phase during summer, representing a sufficient source for the detected IO in the gas phase.

The instrumentation and the spectral analysis are described in Sects. 2 and 3, respectively. The the retrieval of vertical profile information from the MAX-DOAS measurements requires the simulation of the coupled snowpackatmosphere radiative transfer, which is subject of Sect. 4 . The analysis of total iodine in snow pits collected at Neumayer Station is described in Sect. 5. Finally, the diurnal and seasonal variation of the retrieved IO amounts in the atmosphere and snowpack and the total iodine concentrations in snow pit samples are discussed in Sect. 6 .

\section{Instrumental}

The DOAS instrument at Neumayer station $\left(70^{\circ} \mathrm{S}, 8^{\circ} \mathrm{W}\right)$ has been continuously performing atmospheric trace gas measurements since January 1999. Neumayer II (which has been replaced by the new station Neumayer III in austral summer 2008/2009) was located on the shelf ice in front of the Antarctic continent. The measurement site was located at a distance of approximately $15 \mathrm{~km}$ to the open sea in northerly direction, and $5 \mathrm{~km}$ to Atka bay in north-easterly direction.

The Neumayer DOAS instrument has already been described in detail elsewhere (Ferlemann et al., 2000; Frieß et al., 2001, 2004) and is therefore only briefly described here. It consists of two separate spectrograph- detector units consisting of holographic concave gratings and photodiode arrays cooled to $-30^{\circ} \mathrm{C}$ to minimise dark current and detector noise. The instrument covers the wavelength regions 
of 320 to $420 \mathrm{~nm}$ (UV) and 400 to $650 \mathrm{~nm}$ (Vis) with a spectral resolution of approximately 0.5 and $1 \mathrm{~nm}$, respectively. The optical benches of the spectrometer units, made of $5 \mathrm{~mm}$ stainless steel plates, are mounted inside a temperature stabilised, vacuum sealed aluminium vessel, filled with dry argon. The instrument is characterised by an excellent stability, which is crucial for high-quality long-term measurements.

Scattered skylight from the telescope unit is fed to the spectrometers using depolarising quartz fibre bundles. Initially, only zenith-sky measurements were performed, until the telescope unit was replaced by a multi-axis telescope in austral summer 2002/2003. It is equipped with two prisms, each mounted on the axis of a stepper motor. This set-up allows for varying the elevation angle $\alpha$ (the angle between zenith and viewing direction). Skylight is reflected by the prisms at an angle of $90^{\circ}$ and focused on the entrances of the fibre bundles by plano-convex lenses. The entrance optics are located inside a quartz glass tube of $145 \mathrm{~mm}$ diameter, which is integrated into a heated stainless steel housing. The entrance optics has a field of view (FOV) of $1^{\circ}$. The telescope is mounted on the roof of the Neumayer trace gas observatory, at a height of approximately $7 \mathrm{~m}$ over the snow surface. The viewing plane of the telescope is directed to the north.

UV and Vis spectra are recorded with a total integration time of 3 min during the day, at solar zenith angles (SZA) of $\theta<90^{\circ}$. During twilight, the integration time increases to up to $800 \mathrm{~s}$ at $\theta=97^{\circ}$. Only zenith sky measurements are performed for $\theta>85^{\circ}$ as well as for a period of $30 \mathrm{~min}$ around local noon. Otherwise, the measurements are performed sequentially at elevation angles $\alpha$ of $90^{\circ}$ (zenith), $20^{\circ}, 10^{\circ}, 5^{\circ}$, $2^{\circ},-5^{\circ}$ and $-20^{\circ}$. The acquisition of one sequence of elevation angles thus takes about $20 \mathrm{~min}$. Measurements at $-5^{\circ}$ and $-20^{\circ}$, pointing downwards on the snow surface, are performed since 15 September 2007. These measurements contain information on trace gases below the instrument and inside the snowpack, whereas the upward looking viewing directions are mainly sensitive for absorbers in the boundary layer above the instrument and, during twilight, in the stratosphere. The sensitivity of the measurements to the vertical distribution of trace gases will be discussed in detail in Sect. 4.

Offset, dark current, as well as halogen- and mercury calibration spectra necessary for background correction, determination of instrument noise, wavelength calibration and monitoring of the spectral resolution, are recorded automatically each night.

\section{Spectral analysis}

The analysis of the spectra obtained by the Neumayer DOAS instrument is performed using the well established DOAS technique (Platt, 1994; Platt and Stutz, 2008). DOAS allows to determine the integrated concentration of atmospheric trace gases along the light path through the atmosphere, referred to as slant column density (SCD):

$S=\int_{0}^{L} \rho(s) d s$

with $\rho(s)$ being the concentration of the trace gas at location $s$. Note that Eq. (1) is only a very simplified description the real processes in the atmosphere. In practice, the observed SCDs are the weighted average over a manifold of all possible light paths through the atmosphere, and the interpretation of the measurements requires the simulation of the effective light path using a radiative transfer model (Marquard et al., 2000). The SCD depends on the observation geometry, i.e. on SZA $\theta$, elevation angle $\alpha$ and relative solar azimuth angle (SAA) $\phi$.

The SCDs of several absorbers are determined simultaneously using their individual absorption features as fingerprints. According to the Beer-Lambert law, the measured optical density is given by

$$
\begin{aligned}
& \tau_{\text {meas }}(\lambda) \equiv-\ln \left(\frac{I(\lambda)}{I_{o}(\lambda)}\right) \\
& =\int_{0}^{L}\left(\sum_{i} \sigma_{i}(\lambda) \rho_{i}(s)+k_{r}(\lambda, s)+k_{m}(\lambda, s)\right) d s
\end{aligned}
$$

Here, $\sigma_{i}(\lambda, T, p)$ is the temperature and pressure dependent absorption cross section of the $i$ th trace gas, and $k_{r}$ and $k_{m}$ are the extinction coefficients for Rayleigh and Mie scattering, respectively. $I$ and $I_{0}$ are spectra measured at different observation geometries. For MAX-DOAS measurements, usually a zenith sky spectrum is chosen as reference $I_{0}$, whereas $I$ is measured in off-axis geometry, i.e. along any line of sight except the zenith. Since trace gases are also present when measuring $I_{0}$, the spectral analysis yields the differential slant column density (dSCD) $d S=S-S_{\text {ref. }}$.

The DOAS method uses the fact that $k_{r}$ and $k_{m}$ only vary slowly with wavelength and can be approximated by a polynomial of appropriate order $N$, whereas the absorption cross sections $\sigma_{i}$ contain high frequency structures, acting as individual fingerprints for the detection of trace gases. In the spectral analysis procedure, the optical depth is modelled according to

$\tau_{\text {model }}(\lambda)=\sum_{i} \sigma_{i}(\lambda) S_{i}+\sum_{n=0}^{N} c_{n} \lambda^{n}$

Here $\sigma_{i}$ are reference cross sections, usually measured in the laboratory and convolved to the resolution of the spectrometer with the appropriate slit function. To account for the temperature dependence of the cross sections, several reference spectra of the same trace gas at different temperatures can be included in the analysis. 


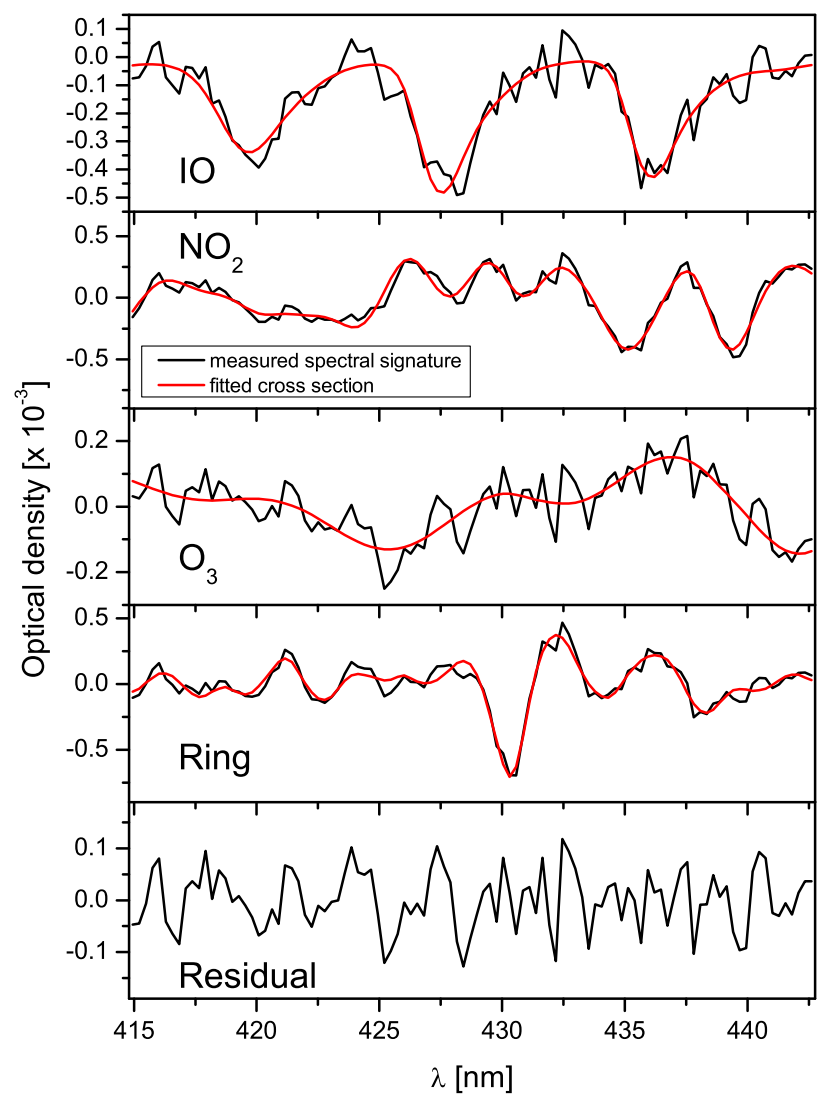

Fig. 1. Example for the retrieval of IO from a spectrum recorded on 8 February 2008 at a solar zenith angle (SZA) of $70^{\circ}$ and an elevation angle of $2^{\circ}$. Black lines: retrieved spectral signature; red lines: scaled cross sections. The root mean squares (RMS) residual amounts to $6.2 \times 10^{-5}$, and a dSCD IO of $(4.61 \pm 0.35) \times$ $10^{13} \mathrm{molec} / \mathrm{cm}^{2}$ is retrieved. The absorption features of $\mathrm{H}_{2} \mathrm{O}, \mathrm{O}_{4}$ and $\mathrm{OClO}$ are not shown.

The retrieval algorithm minimises the difference between measured and modelled optical depth by varying the SCDs $S_{i}$ and polynomial coefficients $c_{n}$ using a non-linear least squares algorithm:

$\chi^{2} \equiv \frac{1}{K_{2}-K_{1}} \sum_{k=K_{1}}^{K_{2}}\left(\tau_{\text {meas }}\left(\lambda_{k}\right)-\tau_{\text {model }}\left(\lambda_{k}\right)\right)^{2} \rightarrow \min$

Here $\lambda_{k}$ is the centre wavelength of the $k$ th detector pixel. The wavelength window of the retrieval, $\left[\lambda\left(K_{1}\right), \lambda\left(K_{2}\right)\right]$, is chosen in order to optimise the signal-to-noise ratio of the trace gases of interest, avoiding disturbing absorption features of other absorbers. The residual root mean square (RMS) $\chi$ quantifies the difference between measured and modelled optical depth and is a measure for the quality of the retrieval.

In the scope of this work, the analysis software Windoas (Fayt and van Roozendael, 2001) is used for the spectral anal- ysis. In addition to the parameters $S_{i}$ and $c_{n}$ in Eq. (3), Windoas supports a shift and squeeze of the pixel-to-wavelength mapping, which compensates for possible changes in the instrument alignment, as well as a non-linear offset to the intensity, accounting for possible detector non-linearities and instrumental stray light.

The dispersion of the Vis spectrometer is determined by fitting a zenith sky spectrum recorded at noon to a high resolution Fraunhofer spectrum (Kurucz et al., 1984), which has been convoluted with the measured mercury emission line at $435 \mathrm{~nm}$.

The retrieval of iodine monoxide is performed in the wavelength interval between 415 and $443 \mathrm{~nm}$ (corresponding to 140 detector pixels), encompassing three IO absorption bands. Apart from IO, the cross sections of ozone, $\mathrm{NO}_{2}, \mathrm{O}_{4}$, $\mathrm{H}_{2} \mathrm{O}$ and $\mathrm{OClO}$ are included in the analysis. All cross sections are convolved with the $\mathrm{Hg}$ emission line at $435 \mathrm{~nm}$ from a mercury lamp spectrum recorded by the Vis spectrometer. A Ring spectrum calculated according to Chance and Spurr (1997) accounts for the filling-in of the Fraunhofer lines by rotational Raman scattering (Grainger and Ring, 1962). A third order polynomial accounts for the broad band spectral features and a polynomial of second order is fitted as a nonlinear intensity offset.

Two fixed Fraunhofer reference spectra $I_{0}$, recorded at noon in zenith, were used for the analysis of the time series: The reference from 20 September 2007 for the analysis of the spectra from July to December 2007, and from 17 February 2008 for the period of January to July 2008. The residual RMS of the IO analysis has a median of $8.2 \times 10^{-5}$, but can be as low as $2.2 \times 10^{-5}$ and rarely exceeds $1.5 \times 10^{-4}$ during daytime.

A typical example for the retrieval of IO at an elevation angle of $2^{\circ}$ is shown in Fig. 1. IO can be clearly detected, with a dSCD of $(4.61 \pm 0.35) \times 10^{13} \mathrm{molec} / \mathrm{cm}^{2}$ corresponding to a peak optical density of $4.8 \times 10^{-4}$. The analysis residual has an RMS of only $6.2 \times 10^{-5}$ and a peak-to-peak optical density of $2.46 \times 10^{-4}$. An example for the evolution of the IO spectral signature under clear sky conditions as a function of elevation angle is shown in Fig. 2. An increase with decreasing elevation angle is observed, with the highest IO dSCD measured when pointing the telescope downwards on the snow surface at $-20^{\circ}$ elevation angle. The Fraunhofer calcium line causes some increase in the residual structure around $430 \mathrm{~nm}$, which can partly be explained by the decrease in intensity at the centre of the line causing higher photon noise.

In addition to IO, the oxygen collision complex $\mathrm{O}_{4}$ at the $477 \mathrm{~nm}$ absorption band is retrieved in the wavelength interval between 450 and $500 \mathrm{~nm}$ using the same retrieval settings as for IO, except that the absorption cross sections for $\mathrm{IO}$ and $\mathrm{OClO}$ are not included. Since the concentration of $\mathrm{O}_{4}$ is proportional to the square of the oxygen concentration and is thus constant (apart from pressure and temperature variations), it is a useful indicator for changes in the 
Table 1. Cross sections included in the spectral analysis of IO.

\begin{tabular}{lll}
\hline Trace gas & Temperature & Reference \\
\hline $\mathrm{IO}$ & $295 \mathrm{~K}$ & Hönninger (1999) \\
$\mathrm{O}_{3}$ & $223 \mathrm{~K}, 243 \mathrm{~K}$ & Bogumil et al. (2000) \\
$\mathrm{NO}_{2}$ & $220 \mathrm{~K}, 294 \mathrm{~K}$ & Vandaele et al. (1998) \\
$\mathrm{O}_{4}$ & & Hermans et al. (2002) \\
$\mathrm{H}_{2} \mathrm{O}$ & $253 \mathrm{~K}$ & Rothman et al. (1998) \\
$\mathrm{OClO}$ & $200 \mathrm{~K}$ & Frost et al. (1995) \\
Ring & & Chance and Spurr (1997) \\
\hline
\end{tabular}

light path, which can be caused by clouds or blowing snow. In fact, MAX-DOAS measurements of $\mathrm{O}_{4}$ can be used to retrieve information on atmospheric aerosols (Wagner et al., 2004; Frieß et al., 2006). Here $\mathrm{O}_{4}$ is used to identify clear sky data as follows: the $\mathrm{O}_{4}$ dSCDs are converted to absolute SCDs by adding the reference SCD determined from a Langley plot based on $\mathrm{O}_{4}$ measurements on a clear day. The measured SCDs are then compared to $\mathrm{O}_{4} \mathrm{SCDs}$ from a lookup table calculated by the McArtim radiative transfer model (see Sect. 4.2) for a pure Rayleigh atmosphere. The lookup table contains simulated $\mathrm{O}_{4}$ SCDs as a function of SZA, SAA and elevation angle. For each elevation angle sequence $\alpha_{1} \ldots \alpha_{M}$, the deviation between modelled $\left(S_{\mathrm{O}_{4}}^{\text {model }}\right)$ and measured $\left(S_{\mathrm{O}_{4}}^{\text {meas }}\right) \mathrm{O}_{4} \mathrm{SCD}$ has been determined according to

$\chi_{\mathrm{O}_{4}}^{2}=\sum_{i=1}^{M}\left(S_{\mathrm{O}_{4}}^{\text {meas }}\left(\alpha_{i}\right)-S_{\mathrm{O}_{4}}^{\text {model }}\left(\alpha_{i}\right)\right)^{2}$

Large $\chi_{\mathrm{O}_{4}}$ values indicate that the atmospheric light path is altered by scattering processes in clouds or blowing snow. The criterion $\chi_{\mathrm{O}_{4}} \leq 2 \times 10^{43} \mathrm{molec}^{2} \mathrm{~cm}^{-5}$ was found to be suitable for the identification of clear-sky conditions. The very good agreement between measured and modelled $\mathrm{O}_{4}$ SCDs confirms that the very low amounts of aerosols in coastal Antarctica do not have a significant impact on the radiative transfer.

\section{Radiative transfer in the atmosphere and snowpack}

\subsection{Qualitative discussion}

The interpretation of MAX-DOAS measurements, and in particular the retrieval of information on the vertical profile of measured trace gases, requires the numerical simulation of the radiative transfer. The basic quantities to be modelled by a radiative transfer model (RTM) which are necessary for profile retrieval are so-called box airmass factors (boxAMFs), which represent the sensitivity of the measured SCD to the partial vertical columns at different altitude layers:

$a_{i j}=\frac{\partial S_{i}}{\partial v_{j}}$

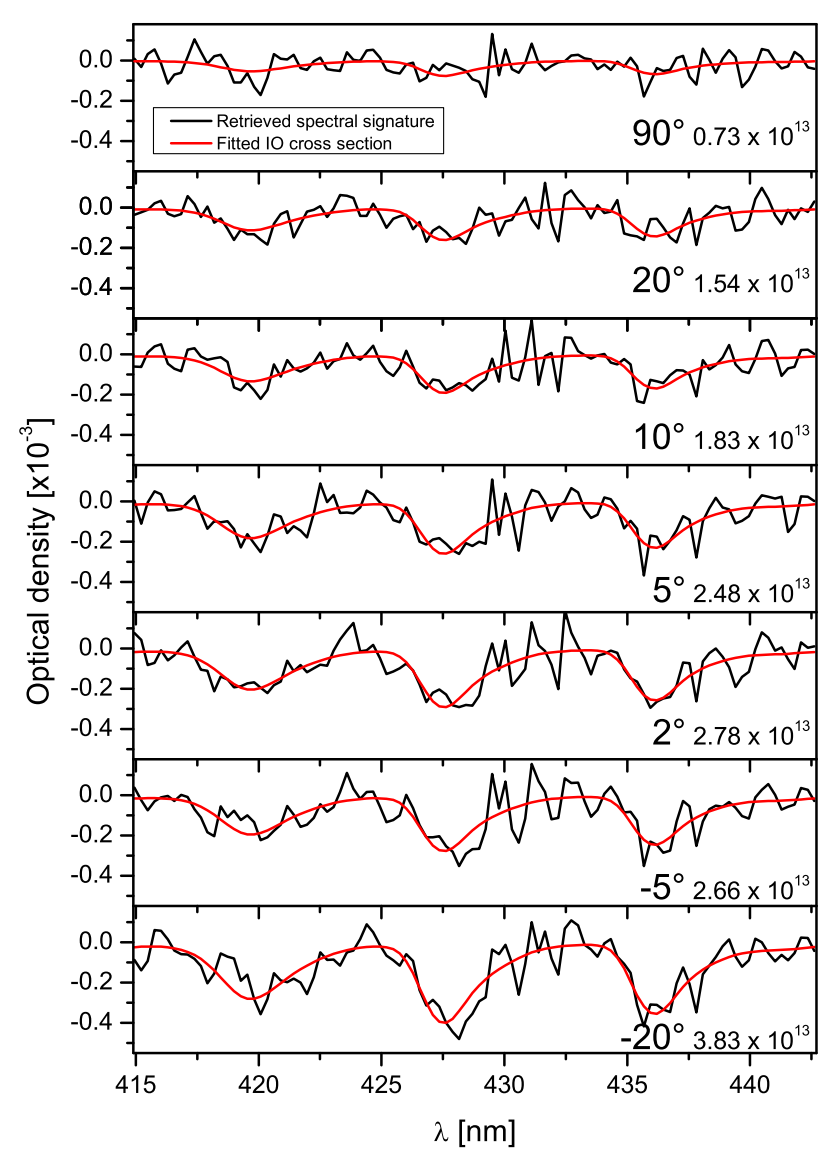

Fig. 2. Retrieved spectral signature of IO for an elevation sequence measured on 2 February 2008. Black lines: retrieved spectral signature; red lines: scaled cross sections. The elevation angles and respective IO dSCDs (in units of $m o l e c / \mathrm{cm}^{2}$ ) are denoted in the graph.

Here $S_{i}$ is the SCD measured at elevation angle $\alpha_{i}$ (for the sake of simplicity, the dependence on SZA and SAA are not considered in the following equations), and the partial vertical column $v_{j}$ is the integrated concentration between altitude layers $z_{j}$ and $z_{j+1}$ :

$v_{j}=\int_{z_{j}}^{z_{j+1}} \rho(z) d z$

For optically thin absorbers (such as IO), the box-AMFs do not depend on the vertical profile, and the SCDs can be calculated according to

$S_{i}=\sum_{j} a_{i j} v_{j}$

Conversely, Eq. (8) can serve as forward model for the retrieval of vertical profiles using the optimal estimation method (Rodgers, 2000). 


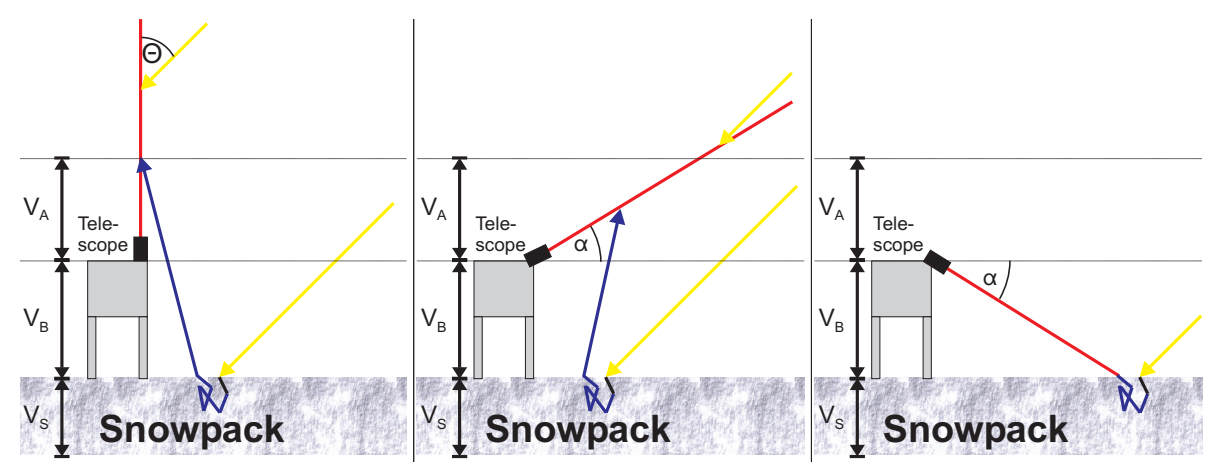

Fig. 3. Simplified sketch of the observation geometry. Left: zenith sky $\left(\alpha=90^{\circ}\right)$; centre: instrument pointing above the horizon $\left(\alpha>0^{\circ}\right)$; right: instrument pointing on the snowpack $\left(\alpha<0^{\circ}\right)$. Yellow: incoming sunlight; blue: light scattered by snowpack; red: instrument line of sight.

The retrieval of vertical profiles from MAX-DOAS measurements has been subject of several publications (e.g., Bruns et al., 2004; Hönninger et al., 2004; Wittrock et al., 2004; Sinreich et al., 2005; Frieß et al., 2006; Wagner et al., 2007). However, ground-based MAX-DOAS measurements have so far only been discussed for conditions with low surface albedo. For observations above snow surfaces, the radiative transfer is more complex and it needs to be considered that:

1. A significant amount of the observed scattered light has been reflected by the snow surface. Under clear sky conditions, the contribution of the upwelling radiation to the total (upwelling plus downwelling) radiation, as measured routinely by pyranometers at Neumayer, is approximately $45 \%$ (data available at http://www.awi.de/en/ infrastructure/stations/neumayer_station/observatories/ meteorological_observatory/radiation_measurements). Thus measurements at any viewing direction, not only when pointing the telescope downwards, are sensitive to trace gases below the instrument.

2. Light hitting the snow surface enters the snowpack and is scattered many times until it leaves the snowpack again. Typical penetration depths of sunlight are several tens of centimetres (Lee-Taylor and Madronich, 2002). Thus scattered light measurements at any viewing direction are sensitive to trace gases in the uppermost layer of the snowpack.

A simplified sketch of this situation is depicted in Fig. 3. It is assumed that the trace gas is located in the planetary boundary layer, i.e. at altitudes below about $2 \mathrm{~km}$. For the following discussion, the trace gas profile is separated into three layers: $v_{a}$ represents the partial VCD above the instrument $\left(z>z_{\text {inst }}\right), v_{b}$ the partial VCD below the instrument $\left(0 \leq z \leq z_{\text {inst }}\right)$ and $v_{s}$ the partial VCD inside the snowpack $(z<0)$.
For zenith-sky measurements $\left(\alpha=90^{\circ}\right.$, left panel of Fig. 3), the majority of direct sunlight (shown in yellow) is scattered into the line of sight (LOS) of the telescope (red line) in the upper troposphere and lower stratosphere, i.e. at altitudes above the trace gas layer. Thus, for surfaces with low albedo, the box-AMF for the layer above the instrument is close to one, whereas zenith-sky measurements are not sensitive for trace gases below the instrument. The situation is different over snow surfaces since the large fraction of diffuse radiation that was in contact with the snowpack (blue line) makes zenith-sky measurements almost equally sensitive for trace gases below the instrument, and also sensitive for the snowpack.

Compared to zenith-sky measurements, off-axis measurements pointing above the horizon $\left(\alpha>0^{\circ}\right.$, middle panel of Fig. 3) have a strongly enhanced sensitivity for trace gases above the instrument, which can be geometrically approximated by $1 / \sin (\alpha)$. They also have an enhanced sensitivity for trace gases below the instrument and inside the snowpack, since the LOS is on average closer to the surface.

Direct sunlight contributes with $85 \%$ to the total downwelling radiation. Thus, mainly directly reflected sunlight is observed when pointing the instrument downwards on the snow surface $\left(\alpha<0^{\circ}\right.$, right panel of Fig. 3). Therefore the box-AMF can be approximated by $1 /|\sin \alpha|+1 / \cos \theta$ for the layer below the instrument, and by $1 / \cos \theta$ for trace gases above the instrument. It is obvious that downward looking measurements are particularly sensitive for trace gases inside the snowpack, since the majority of the detected light has undergone multiple scattering in the uppermost snow layer. Multiple scattering also causes the photons to at least partly lose their memory for the incident direction, and the radiation leaves the snowpack diffusely with a more or less complex bidirectional reflectance density function (BRDF) (Grenfell et al., 1994). It can therefore be expected that, for downward looking viewing directions, the box-AMF for the snowpack has a dependency on the viewing direction weaker than $1 /|\sin \alpha|$. 
However, high trace gas concentrations below the instrument and inside the snowpack are necessary to cause a detectable signal. Given that the telescope of the Neumayer instrument is located at a height of $z_{\text {inst }}=7 \mathrm{~m}$ above the snow surface, and with a typical error of the IO dSCD of $\Delta S=3.5 \times 10^{12} \mathrm{molec} / \mathrm{cm}^{2}$, an average concentration below the instrument of $\Delta \rho_{b}=\Delta S / z_{\text {inst }} \times(1 /|\sin \alpha|+1 / \cos \theta)^{-1} \approx$ $3.5 \times 10^{8} \mathrm{molec} / \mathrm{cm}^{3}$, corresponding to a mixing ratio of about $15 \mathrm{ppt}$, is required to cause a signal that exceeds the retrieval error at an elevation angle of $\alpha=-5^{\circ}$ and an SZA of $\theta=70^{\circ}$. Concentrations inside the snowpack need to be even higher to be detectable, since radiation penetrates the snowpack only down to some tens of centimetres.

Now the findings of this qualitative discussion of the atmosphere-snowpack radiative transfer will be applied to measurements of IO at Neumayer. As an example, clear-sky IO dSCDs from 17 February 2008 are shown in Fig. 4. The IO dSCDs are characterised by the following features:

1. For viewing directions above the horizon $\left(\alpha>0^{\circ}\right)$, the IO dSCDs increase monotonically with decreasing elevation angle.

2. IO dSCDs from the downward viewing directions $\left(-5^{\circ}\right.$ and $-20^{\circ}$ ) are of similar magnitude as the measurements at $+2^{\circ}$.

3. IO dSCDs at $-20^{\circ}$ are similar to or even larger than those at $-5^{\circ}$.

Feature (1) can be caused both by IO located above and below the instrument. Feature (2) indicates that a significant fraction of IO is located below the instrument (either in the atmosphere or inside the snowpack). Since the dSCDs do not vary proportional to $1 /|\sin \alpha|$ for different downward viewing directions, the only explanation for feature (3) is that the majority of the detected IO is located inside the snowpack.

\subsection{Radiative transfer modelling and profile retrieval}

The coupled snowpack-atmosphere radiative transfer is modelled using the McArtim Monte Carlo radiative transfer model, which is the successor of Tracy 2 (Wagner et al., 2007; Deutschmann, 2008). It simulates an ensemble of photons in backward mode, i.e. photons are emitted from the telescope and their paths from the telescope to the Sun is modelled (Marshak and Davis, 2005). The box-AMFs (or in general weighting functions of atmospheric parameters) are computed as weighted means over the photon ensemble.

The model atmosphere is subdivided into layers of $100 \mathrm{~m}$ thickness up to an altitude of $3 \mathrm{~km}$, and on a coarser grid up to $100 \mathrm{~km}$. The lowermost layer extends from the snow surface up to an altitude of $7 \mathrm{~m}$, which is the location of the telescope. Pressure and temperature vertical profiles are adapted from a representative ozone sounding at Neumayer. No aerosols are included in the model atmosphere, which is justified by the

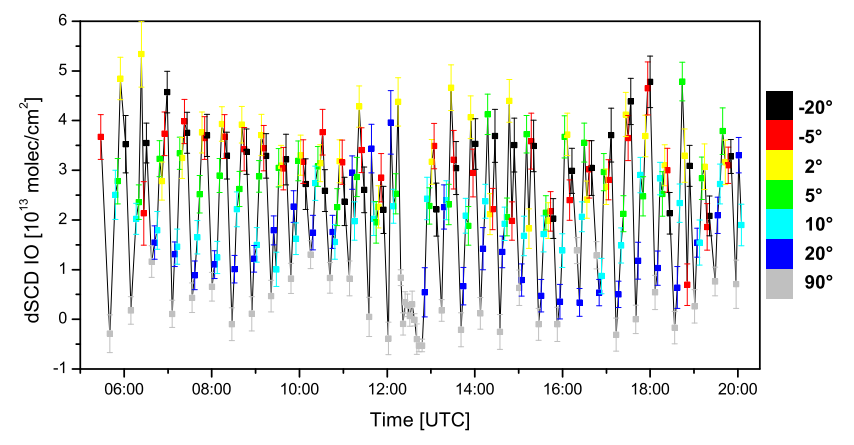

Fig. 4. IO dSCDs observed on 17 February 2008. Different colours indicate the elevation angle as denoted in the legend. Note the high IO dSCDs found at negative elevation angles, i.e. when the instrument looked down to the snowpack, which are similar to the observations at $+2^{\circ}$ elevation angle.

good agreement between modelled and measured clear-sky $\mathrm{O}_{4}$ dSCDs, confirming that the simulation of a pure Rayleigh atmosphere yields realistic results in this very clean environment.

For the simulation of the snowpack radiative transfer, a logarithmic height grid extending down to a depth of $1 \mathrm{~m}$ is used. The thickness of the snow layers is $1 \mathrm{~mm}$ at the top, and is doubled for each following layer. The snowpack is basically treated as a very dense aerosol, using a Henyey-Greenstein phase function (Henyey and Greenstein, 1941). A snow extinction coefficient of $k_{m}=6 \mathrm{~cm}^{-1}$ has been adapted from King and Simpson (2001), and the single scattering albedo as well as the asymmetry parameter are set to $\omega=0.999982$ and $g=0.89$ according to Lee-Taylor and Madronich (2002).

A lookup table of IO box-AMFs at $\lambda=430 \mathrm{~nm}$ as a function of elevation angle, SZA and SAA has been calculated using an ensemble of 10000 photons for each viewing geometry. Due to the large number of scattering events inside the snowpack, the calculation of the lookup table represents a quite large computational effort, requiring about one week of computation time on a state of the art dual core personal computer.

Modelled Box-AMFs for an SZA of $\theta=70^{\circ}$ and SAA of $\phi=90^{\circ}$ are shown if Fig. 5. As expected, the box-AMFs for the atmosphere above the instrument strongly increase with decreasing elevation angle, from 4.1 in zenith to 32.4 at $2^{\circ}$ in the first $100 \mathrm{~m}$ above the telescope. Apart from the $2^{\circ}$ viewing direction, the variation of the box-AMFs with altitude is weak, which implies that there is only limited information on the vertical profile above the instrument. Interestingly, downward viewing measurements have a higher sensitivity for the atmosphere above the instrument than zenith-sky measurements, with box-AMFs of 7.0 and 5.0 for the $-5^{\circ}$ and $-20^{\circ}$ viewing directions, respectively. 


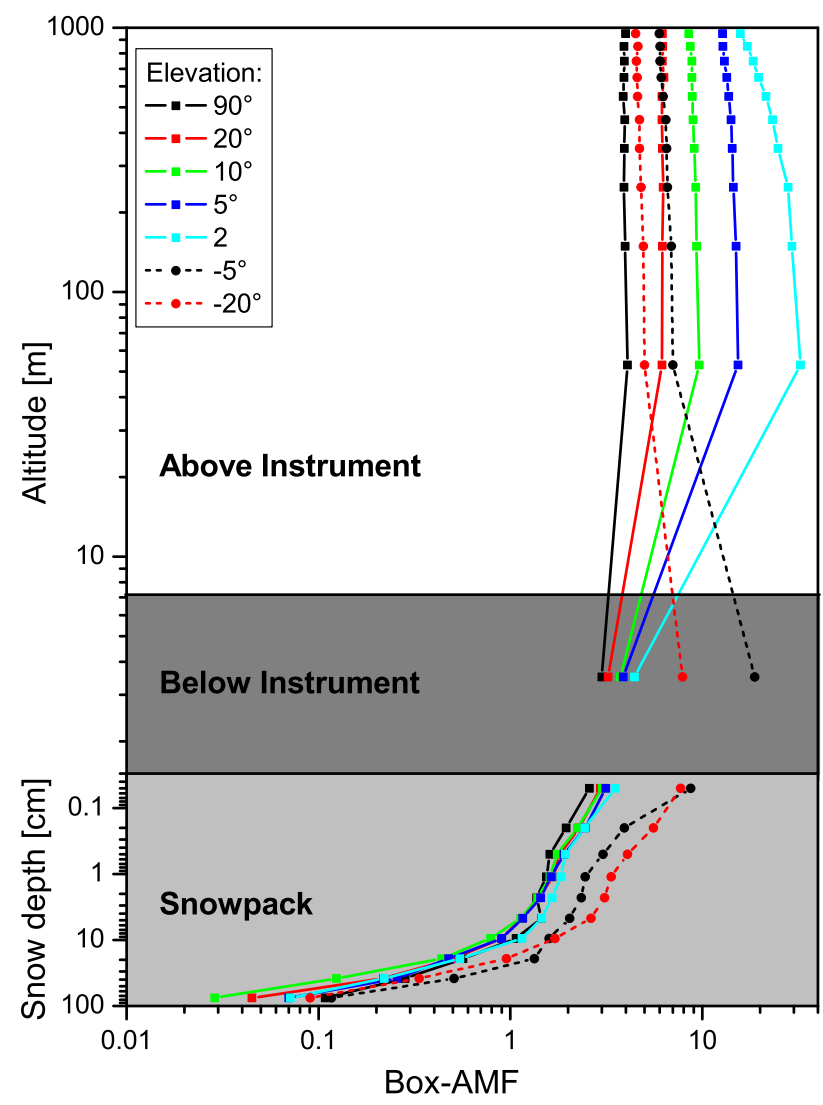

Fig. 5. Modelled box-airmassfactors (AMFs) for $\theta=70^{\circ}$ and $\phi=90^{\circ}$ for different elevation angles as denoted in the legend. Note the double-logarithmic scale and the different height scales for snowpack and atmosphere.

Downward viewing directions are most sensitive for the atmosphere below the instrument, with box-AMFs of 18.7 and 7.9 for the $-5^{\circ}$ and $-20^{\circ}$ viewing directions, respectively. These values are significantly higher than calculated from the simple geometric approximation discussed in Sect. 4.1 (14.2 and 5.8, respectively). The sensitivity of the upward looking viewing directions to the atmosphere below the instrument ranges from 3.0 in zenith sky to 4.4 at $2^{\circ}$ elevation.

For the uppermost $1 \mathrm{~mm}$ of the snowpack, box-AMFs of the downward viewing directions are quite similar, with values of 8.7 and 7.7 for the $-5^{\circ}$ and $-20^{\circ}$ viewing directions, respectively. The box-AMFs of the upward viewing directions for this thin layer of snow range between 2.6 (zenith) and $3.5\left(2^{\circ}\right)$. However, the sensitivity of the MAX-DOAS measurements to trace gases in the snowpack quickly decreases with depth, with attenuation depths of the box-AMFs (i.e., the depth at which the box AMF reaches half of its surface value) ranging between 5 and $10 \mathrm{~cm}$.

The box-AMFs calculated for the snowpack are subject of large uncertainties for several reasons. First, the statisti- cal noise of the Monte Carlo simulations becomes very high in the lowermost snow layers owing to the small number of modelled photons reaching these depths. However, this is of minor importance since the contribution of light from deep snow layers to the observed signal is small. Second, the optical properties of snow and in particular the extinction coefficient vary largely, as shown by different studies (e.g., Warren (1982); King and Simpson (2001), and references therein), which is partly owing to the variability in snow density, grain size and amount of impurities. Third, the representation of snow properties in the model is very simplified. The snow surface is treated as a horizontally and vertically homogeneous and flat layer. The topology of the snow surface, such as sastrugi (i.e., grooves or ridges formed by wind erosion) and wind ripples which affect the radiative transfer, are not considered. Furthermore, snow properties vary seasonally owing to temperature variations and changes in morphology due to ageing processes, but also due to dispersion and deposition of snow crystals during blizzards. The RTM also does not consider that the measurements, in particular at low elevation angle pointing northwards, are affected by light scattered both by the shelf ice and the sea ice due to the vicinity of Neumayer station to the ocean.

To retrieve the IO partial VCDs $v_{a}, v_{b}$ and $v_{s}$ introduced in Sect. 4.1, the vertical resolution of the modelled box-AMFs is degraded to these three layers. A thickness of $1 \mathrm{~km}$ is chosen for the layer above the instrument. Inside the snowpack, a box profile shape with a constant concentration down to a depth of $25 \mathrm{~cm}$ is assumed, corresponding to the typical penetration depth of radiation which can cause a photochemical production of IO.

The resulting snowpack box-AMFs for the downward viewing directions are shown in Fig. 6 as a function of SZA and SAA. Due to the averaging procedure with the assumed box profile as weight, the total AMFs for the snowpack are significantly smaller than the values at the surface from the height-resolved box-AMFs shown Fig. 5. As expected, the snowpack box-AMF for the $-5^{\circ}$ viewing direction varies much stronger with viewing geometry than at $-20^{\circ}$ elevation. In particular, the model predicts that measurements at $-5^{\circ}$ are almost insensitive to trace gases in the snowpack at high SZA and SAA around zero, i.e. if the light hits the snow surface in a shallow angle and the instrument points towards the Sun. As already discussed above, this would only occur under idealised conditions if the snow surface would be completely flat. To account for variations of surface tilt due to sastrugis and wind ripples, a triangular smoothing is applied to the snowpack box-AMFs which serve as weighting functions for the retrieval algorithm described in the following.

Given that the degrees of freedom for signal, which express the number of independent pieces of information contained in the measurements, is very close to 3 (in most cases > 2.99), the retrieval of three partial VCDs $v_{a}, v_{b}$ and $v_{s}$ from MAX-DOAS measurements at 7 viewing directions 

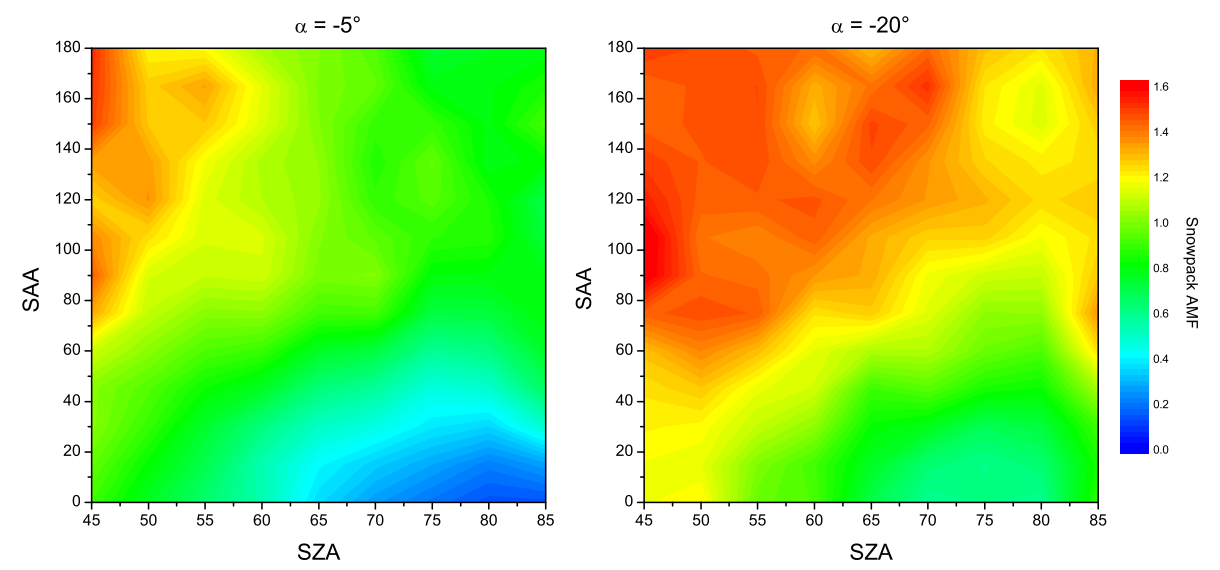

Fig. 6. Modelled box-AMFs for the snowpack as function of SZA and solar azimuth angle (SAA) for the downward viewing directions. Left: $\alpha=-5^{\circ}$; right: $\alpha=-20^{\circ}$.

represents a well constrained problem. Therefore no additional a priori constraints are necessary, and the partial VCDs can be determined using a least squares algorithm, minimising the deviation between measured and modelled SCDs:

$\chi_{R}^{2} \equiv(\boldsymbol{y}-\mathbf{K} \boldsymbol{v})^{T} \mathbf{S}_{\epsilon}{ }^{-1}(\boldsymbol{y}-\mathbf{K} \boldsymbol{v}) \rightarrow \min$

The estimate of the state vector $\hat{\boldsymbol{v}}=\left(\hat{\boldsymbol{v}}_{a}, \hat{\boldsymbol{v}}_{b}, \hat{\boldsymbol{v}}_{s}\right)$ is then given by

$\hat{\boldsymbol{v}}=\left(\mathbf{K}^{T} \mathbf{S}_{\epsilon}{ }^{-1} \mathbf{K}\right)^{-1}\left(\mathbf{K}^{T} \mathbf{S}_{\epsilon}{ }^{-1} \boldsymbol{y}\right)$

The vector $\boldsymbol{y}=\left(S_{1}, . ., S_{M}\right)$ contains the measured IO SCDs at the $M=7$ different viewing angles of an elevation sequence, the elements of the weighting function $K$ are the box-AMFs $a_{i j}$, and the measurement error covariance $S_{\epsilon}$ is a $M \times M$ matrix with the square of the measurement errors as diagonal elements and the non-diagonal elements set to zero. The retrieval error is represented by the covariance matrix of the state vector:

$\hat{\mathbf{S}}=\mathbf{K}^{T} \mathbf{S}_{\epsilon}{ }^{-1} \mathbf{K}$

For a retrieval based on differential instead of absolute SCDs, the weighting functions need to be replaced by differential box-AMFs, $K_{i j}=a_{i j}-a_{0 j}$, by subtracting the boxAMFs of the reference measurement at $\alpha_{0}=90^{\circ}$.

To convert differential to absolute SCDs, a two stage process is used similar to the approach by Hendrick et al. (2007) for stratospheric $\mathrm{BrO}$ profiling. First, a retrieval of the whole time series is performed based on IO dSCDs with a fixed Fraunhofer reference spectrum. From the resulting partial VCDs, the according reference SCDs are calculated, and their error weighted average for clear sky conditions (determined using the $\chi_{\mathrm{O}_{4}}$ criterion as defined in Sect. 3 ) is added to the dSCDs, yielding absolute SCDs. In a final step, partial VCDs are retrieved using absolute IO SCDs. This improves

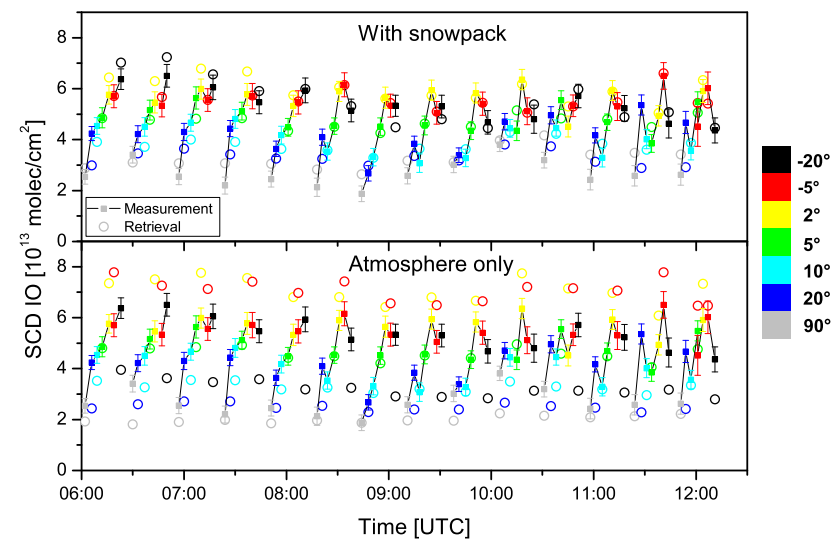

Fig. 7. Comparison of measured (squares with error bars) and modelled (open circles) IO SCDs in the morning of 2 February 2008. The colours indicate the elevation angle as denoted in the legend, and data points from individual elevation sequences serving as input for a single retrieval are connected by black lines. Top panel: retrieval using three layers (above and below the instrument as well as snowpack). Bottom panel: snow layer excluded from the retrieval, i.e. it is assumed that all IO is located in the atmosphere.

the accuracy and stability of the results, since the algorithm based on SCDs has one retrieval parameter less (i.e., the reference SCD) and thus a higher information content than the retrieval with dSCDs. Furthermore, this improves the stability of the results with respect to varying atmospheric conditions, such as blowing snow.

A comparison between measured and modelled IO SCDs is shown in Fig. 7. The upper panel shows the results for the standard retrieval with three layers, i.e. under the assumption that IO can be located above and below the instrument as well as in the snowpack. In this case, modelled and measured 


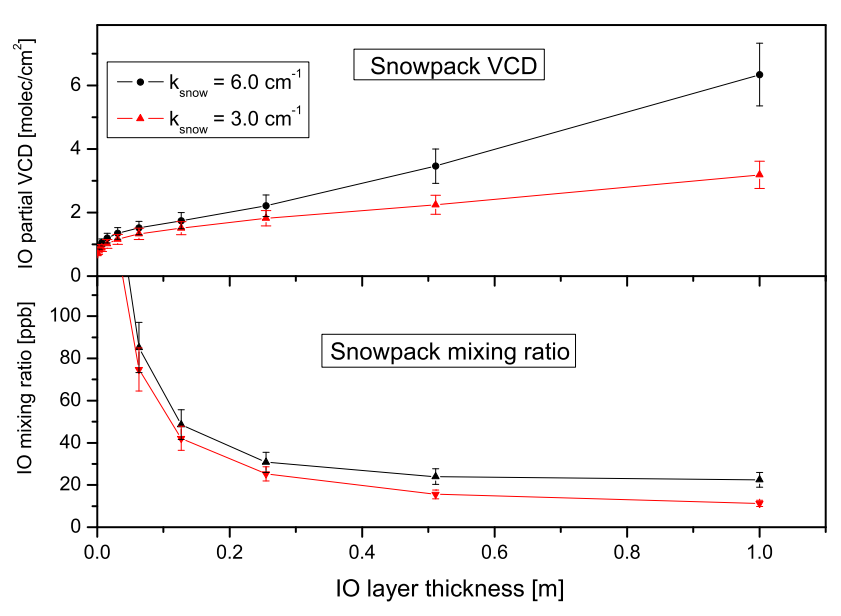

Fig. 8. Retrieved IO partial vertical column densities (VCDs) (upper panel) and IO mixing ratios (lower panel) inside the snowpack as a function of snowpack profile depth. Black line: snow extinction of $6 \mathrm{~cm}^{-1}$ (standard scenario), red line: snow extinction of $3 \mathrm{~cm}^{-1}$. The retrievals were performed for a measurement on 2 February 2008, 11:00 UT.

values are in good agreement and the observed variation of the IO SCDs with elevation angle is well reproduced by the model. A much poorer agreement between modelled and measured SCDs is achieved if the snowpack is excluded from the retrieval, i.e. if only two atmospheric layers above and below the instrument are retrieved and the snowpack concentration is set to zero. As shown in the lower panel of Fig. 7, in this case the model strongly underestimates the IO SCDs of the $-20^{\circ}$ viewing direction, and the modelled $+2^{\circ}$ and $-5^{\circ} \mathrm{SCDs}$ are too high. This again illustrates that the measurements at Neumayer can only be explained if a significant fraction of the observed IO is located inside the snowpack. On the other hand, the retrieval is also not able to reproduce the measurements if IO is only retrieved below the instrument and inside the snowpack (not shown), indicating that there is a significant fraction of IO above the instrument as well.

Instead of the snowpack, IO could also be present in the atmosphere close to the snow surface, and multiple scattering inside blowing snow could lead to an amplification of the light path. To test this hypothesis, retrievals treating the snow surface as a Lambertian reflector (i.e., no IO inside the snowpack), and including a layer of blowing snow of $10-50 \mathrm{~cm}$ height above the surface, were performed with different extinction coefficients of the blowing snow $\left(1 \mathrm{~m}^{-1}\right.$ and $\left.3 \mathrm{~m}^{-1}\right)$. These model runs were able to reproduce the measurements as well, yielding around $10 \mathrm{ppt}$ of IO in the blowing snow layer. However, in this case the IO signal of the downward viewing directions should be below the detection limit at low wind speeds. Since no correlation between downward looking IO SCDs and wind speed has been observed, the hypoth- esis of an IO signal from close to the surface, amplified by blowing snow, can be ruled out.

Similar agreement between measured and modelled IO dSCDs under clear sky conditions as shown in Fig. 7 has been achieved throughout the period of September 2007 to April 2008, except occasionally at low SZA when the Sun was located behind the instrument $\left(\theta \approx 180^{\circ}\right)$, i.e. around midnight in polar summer. Several sensitivity studies were performed to test the robustness of the retrieval. Different shapes of the IO profile inside the snowpack were assumed (see Sect. 4.3), and also retrievals with a height resolved representation of the IO profile inside the snowpack and above the instruments (with the vertical grid as in Fig. 5) based on optimal estimation were performed. In all cases, IO was detected inside the snowpack unambiguously.

\subsection{Sensitivity on profile shape and snowpack extinction}

The MAX-DOAS measurements of scattered light performed at Neumayer Station do not contain information on the IO profile shape inside the snowpack. However, the retrieved amount of IO inside the snowpack depends on the assumed profile shape, and also on the snow extinction coefficient. To investigate the sensitivity of the retrieval results on these parameters, a representative clear-sky measurement was chosen ( 2 February 2008, 11:00 UT), and retrievals were performed assuming a constant IO concentration down to varying depths inside the snowpack. The resulting partial IO VCDs are shown in Fig. 8. Apart from the standard scenario with a snowpack extinction coefficient of $6 \mathrm{~cm}^{-1}$ (black lines), also calculations for half the extinction coefficient are shown (red lines).

The retrieved IO VCD inside the snowpack (upper panel of Fig. 8) increases with profile depth because the total snowpack AMF (the weighted sum of the box-AMFs, see Fig. 5) decreases and the VCD is given by the ratio between SCD and AMF. The lack of sensitivity to layers below a certain depth leads to a linear increase of the snowpack VCDs for profile depths larger than $\approx 25 \mathrm{~cm}$. Thus the average mixing ratio (proportional to the ratio between VCD and profile depth) remains constant for profile depths larger than $\approx 25 \mathrm{~cm}$, with values around $20 \mathrm{ppb}$ (lower panel of Fig. 8). This value can be considered as a lower limit for the snowpack IO mixing ratio. The assumption of IO being located only close to the surface would lead to mixing ratios exceeding $100 \mathrm{ppb}$ if the layer would be thinner than $5 \mathrm{~cm}$. Since such high IO amounts are in contradiction to the measurements of total iodine in snow (see Sect. 6.1), the detected IO is likely to be located in the snow bulk rather than being concentrated in a thin layer close to the snow surface.

Since a decrease in snow density leads to an increase in penetration depth of light, the retrieved IO mixing ratio is reduced to about half its value (about $10 \mathrm{ppb}$ for a layer depth of $1 \mathrm{~m}$ ) when halving the snowpack extinction coefficient (red line). 
From these sensitivity studies it is obvious that the MAXDOAS measurements at Neumayer can provide neither information on the partial IO VCD inside the snowpack nor on the IO mixing ratio, since both strongly depend on the assumed vertical profile inside the snowpack and on the snowpack optical properties. The results presented in Sect. 6 are based on the assumption that IO has a constant concentration profile inside first $25 \mathrm{~cm}$ the snowpack, and therefore provide only a rough estimate of the snowpack IO VCDs and mixing ratios.

\section{Analysis of total iodine from snow pit samples}

A $198 \mathrm{~cm}$ deep snow pit was excavated directly south of the Neumayer II research station during the Austral summer 2008/2009 field campaign of the Alfred Wegener Institute (AWI) $\left(70.7137^{\circ} \mathrm{S}, 8.4179^{\circ} \mathrm{W}\right)$. All snow pit samples were taken with $60 \mathrm{ml}$ PE beakers which were pushed into the snow pit wall, slightly overlapping the same snow layer, which allowed for a sample resolution of about $5 \mathrm{~cm}(10$ 15 samples per year). All beakers had been pre-cleaned with ultra-pure water, until the conductivity of the water was less than $0.5 \mu \mathrm{S} \mathrm{cm}^{-1}$. After cleaning, the beakers were dried in a contamination free vacuum oven and directly sealed in PEbags until employed in the snow pit. After sampling, the beakers were sealed for transportation. All snow pit samples were transported in a frozen state $\left(-20^{\circ} \mathrm{C}\right)$ to the cold room facility of the Alfred Wegener Institute at Bremerhaven, Germany. In general, methanesulphonate $\left(\mathrm{MS}^{-}\right), \mathrm{Cl}^{-}, \mathrm{NO}_{3}^{-}$, $\mathrm{SO}_{4}^{2-}, \mathrm{Na}^{+}, \mathrm{NH}_{4}^{+}, \mathrm{K}^{+}, \mathrm{Mg}^{2+}$, and $\mathrm{Ca}^{2+}$ were quantified by gradient ion chromatographic (IC) analysis on a Dionex ICS 2000 equipped with suppressor units, and Dionex CS12 and Dionex AS18 separator columns for cations and anions, respectively (Göktas, 2002; Göktas et al., 2002). In short, the uncertainty for the measured ionic concentrations discussed in this study was approximately $3-5 \%$ for the main components $\mathrm{MS}^{-}, \mathrm{Cl}^{-}, \mathrm{NO}_{3}^{-}, \mathrm{SO}_{4}^{2-}, \mathrm{Na}^{+}$, increasing to between $10 \%$ and $20 \%$ for the minor species $\mathrm{NH}_{4}^{+}, \mathrm{K}^{+}, \mathrm{Mg}^{2+}$, and $\mathrm{Ca}^{2+}$. After major ion measurements, the samples were refrozen and transported to Lake Constance (Germany) for total soluble iodine (TSI) measurement. For TSI analysis, samples were allowed to warm to room temperature and, after addition of ${ }^{187} \mathrm{Re}$ as an internal standard, were measured by a Perkin Elmer Elan 6100 inductively coupled mass spectrometer (ICP-MS), peaking hopping on the masses ${ }^{127} \mathrm{I}$ and ${ }^{79} \mathrm{Br}$. This method has been used for iodine and bromine quantification in snow and rain samples from mid-latitude sites by Gilfedder et al. (2007a,b) and Gilfedder et al. (2008) and similar methods have been used by Moran et al. (1999) for rain in the United Sates. Replicate measurements of selected samples ranged from $0.8-13 \%$, except when approaching the detection limit $(3 \sigma=30 \mathrm{ng} / \mathrm{l})$, where the relative standard deviation could be as high as $20-30 \%$. The highest absolute $1 \sigma$ error was $\pm 65 \mathrm{ng} / \mathrm{l}$. The accuracy was assessed by measuring standard reference material BCR-611 (a groundwater sample), which is certified for bromide and gives indicative values for iodine of $9.3 \pm 1.3 \mu \mathrm{g} / \mathrm{l}$. We diluted BCR-611 1:5 so that the concentrations would be in the expected range of the samples, and recovered an iodine concentration of $10.1 \mu \mathrm{g} / \mathrm{l}$, within the uncertainty given in the certificate. The snow density was measured in the field by weighing know volumes of snow/firn at each sampling point. Oxygen isotope data was measured at the AWI by Dr. Hans Oerter using standard mass spectrometric techniques (Oerter et al., 2004). All oxygen isotope data is given relative to Standard Mean Ocean Water (SMOW).

\section{Results and discussion}

\subsection{Iodine in snow pit samples}

$\delta^{18} \mathrm{O}$ isotope signatures and the concentration of anions nitrate and methanesulphonic acid (MSA) were used to separate winter/summer snow accumulation periods in the snow profile. $\delta^{18} \mathrm{O}$ gives an indication of the regional temperature, and a clear separation of Antarctic winter and summer during snow deposition. While some problems using $\delta^{18} \mathrm{O}$ as a seasonal tracer have been observed for low snow accumulation sites such as Dronning Maud Land, high accumulation coastal areas such as Neumayer should give reliable data (Helsen et al., 2005). Nitrate and MSA formation are both dependent on photolytic processes, with MSA being a product of dimethyl sulphide oxidation by $\mathrm{OH}$ radicals during abstraction and addition oxidation pathways (von Glasow and Crutzen, 2004). It is thought that most of the nitrate excess (compared to background winter levels) observed during spring and summer originates from sedimentation from the stratosphere, and to a lesser degree (and perhaps latter in the summer season) from photolytic release of nitrate from the snow pack (Wagenbach et al., 1998; Jones et al., 2001; Weller et al., 2004; Savarino et al., 2007). Thus these three independent indicators should give a reliable representation of summer/winter stratification in the snow pit, and can be clearly seen in Fig. 9. A similar approach has been adopted by Hur et al. (2007) for trace metals in snow pits from Lambert Glacier basin, East Antarctica.

The iodine concentrations in the winter ( $\max 650 \mathrm{ng} / \mathrm{l}$ water equivalent) were lower than observed at mid latitude sites $(<1-4.4 \mu \mathrm{g} / \mathrm{l}$, average around $1 \mu \mathrm{g} / \mathrm{l})$ (Gilfedder et al., 2007b, 2008; Aldahan et al., 2009). However, iodine concentrations showed a clear seasonal cycle, with peak concentrations in winter. Indeed, during the austral summer iodine concentrations approached the detection limit, and in some cases could not be detected at all. Given that atmospheric iodine concentrations are expected to be significantly higher during the summer than the winter (Saiz-Lopez et al., 2007b) due to higher biological activity in the sea ice, and assuming that the iodine is not released from the snow prior to 


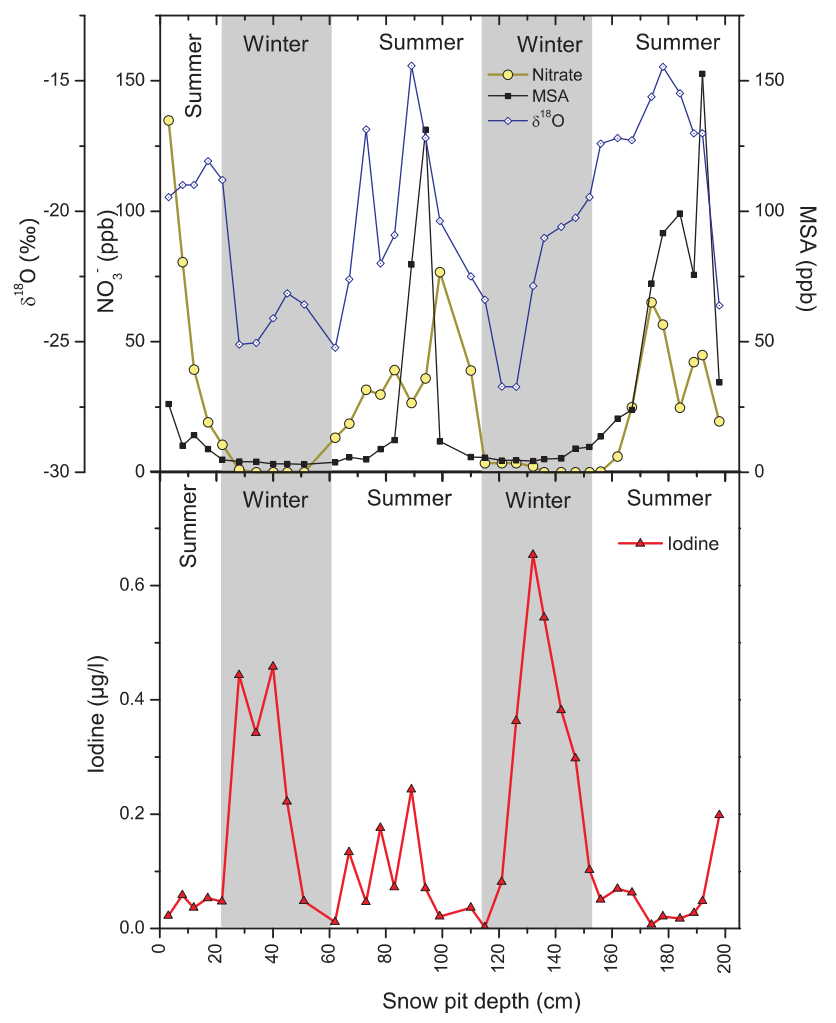

Fig. 9. Seasonal variation of total soluble iodine (lower panel), $\delta^{18} \mathrm{O}$, MSA and nitrate (upper panel) measured in snow pit samples at Neumayer Station.

deposition (very unlikely given mid-latitude measurements of deposited snow), there must be significant and efficient iodine release from the snowpack. This can also be seen by the very rapid decrease in iodine levels with the start of spring. By using the winter iodine concentrations in the snow pit as minimum iodine concentrations, and taking the snow/firn density measured in the snow pit $\left(0.46 \mathrm{~g} / \mathrm{cm}^{3}\right)$, it is possible to calculate a snow/firn iodine concentration of $300 \mu \mathrm{g} / \mathrm{m}^{3}$ snow/ice. If this is released directly into gasfilled pore spaces it could lead to $\approx 94 \mathrm{ppbv}$ of gas phase iodine. This is probably the minimum amount of iodine that could be released from the snow pack, as the iodine concentrations in falling snow during spring and summer are likely to be somewhat higher than observed in winter, as observed in the gas-phase at Halley Bay (Saiz-Lopez et al., 2007b) and in aerosols at the South Pole (Tuncel et al., 1989). Moreover, Heumann et al. (1987) have measured a maximum iodine concentration of $1800 \mathrm{ng} / \mathrm{l}$ in snow samples taken near Neumayer station in February 1985. These samples were measured by isotope dilution thermal ionisation mass-spectrometry.
The clear seasonal trend in iodine concentrations in the snow pit indicates that there must be very little vertical migration of iodine within the snow pack. If photolytic reactions were able to volatilise iodine at significant depths $(>5-10 \mathrm{~cm})$, the iodine accumulated over winter would be released to the atmosphere, resulting in little observable seasonal variation. However, the obvious winter peak in iodine levels and rapid decrease with the onset of spring show that iodine is only volatilised from the upper most sections, with iodine deposited in the winter accumulated snow remaining relatively stable.

\subsection{Diurnal variation of IO}

Partial IO VCDs above and below the instrument as well as in the snowpack, derived using the retrieval algorithm described in Sect. 4.2, are shown in Fig. 10 for a period of clear sky (14 February 2008).

Partial IO VCDs above the instrument (panel b) vary between $(1-4) \times 10^{12} \mathrm{molec} / \mathrm{cm}^{2}$. Assuming a uniform distribution of IO in a layer of $1 \mathrm{~km}$ height, this corresponds to mixing ratios of only 0.4 to $1.6 \mathrm{ppt}$. The diurnal variation of IO above the instrument is characterised by a minimum around local noon, and slightly higher amounts in the evening than in the morning. This diurnal variation is similar to predictions from photochemical model calculations (Vogt et al., 1999), where the IO minimum at noon is caused by the reaction of $\mathrm{HO}_{2}$ with $\mathrm{IO}$ to $\mathrm{HOI}$, and the am/pm asymmetry by a built-up of $\mathrm{I}_{2} \mathrm{O}_{2}$ by $\mathrm{IO}$ self reaction during the day. However, $\mathrm{HO}_{2}$ concentrations at the West Antarctic coast are about a factor of five smaller than modelled by Vogt et al. for mid-latitude conditions, and $\mathrm{NO}_{2}$ concentrations around 3 ppt measured in the boundary layer at Neumayer (Jones et al., 1999; Jacobi et al., 2000) are likely to be too small to cause a significant formation of $\mathrm{IONO}_{2}$ during the day. Another possible explanation for the noon minimum of IO above the instrument is a break-up of the boundary layer and a mixing in of free tropospheric air low in IO.

Inside the snowpack, IO VCDs of up to $5 \times 10^{13} \mathrm{molec} / \mathrm{cm}^{2}$ are retrieved, with a minimum around noon which might be caused by the formation of $\mathrm{HOI}$ by reaction with $\mathrm{HO}_{2}$. This corresponds to extremely high IO mixing ratios of up to $50 \mathrm{ppb}$ inside the snowpack (lower panel of Fig. 11). As discussed in Sect. 6.1, the snow pit measurements indicate that iodine accumulated in the particulate phase during winter is released to the gas phase as soon as sunlight is available, leading to more than $100 \mathrm{ppb}$ of iodine in the snow interstitial. Thus particulate iodine observed in the snow pit represents a sufficient reservoir to explain IO mixing ratios of $\approx 50 \mathrm{ppb}$ observed by MAX-DOAS.

However, from our current knowledge of iodine photochemistry, it is difficult to explain how gas phase concentrations of IO in the order of several tens of ppb can be sustained. Considering only gas phase chemistry, the lifetime 


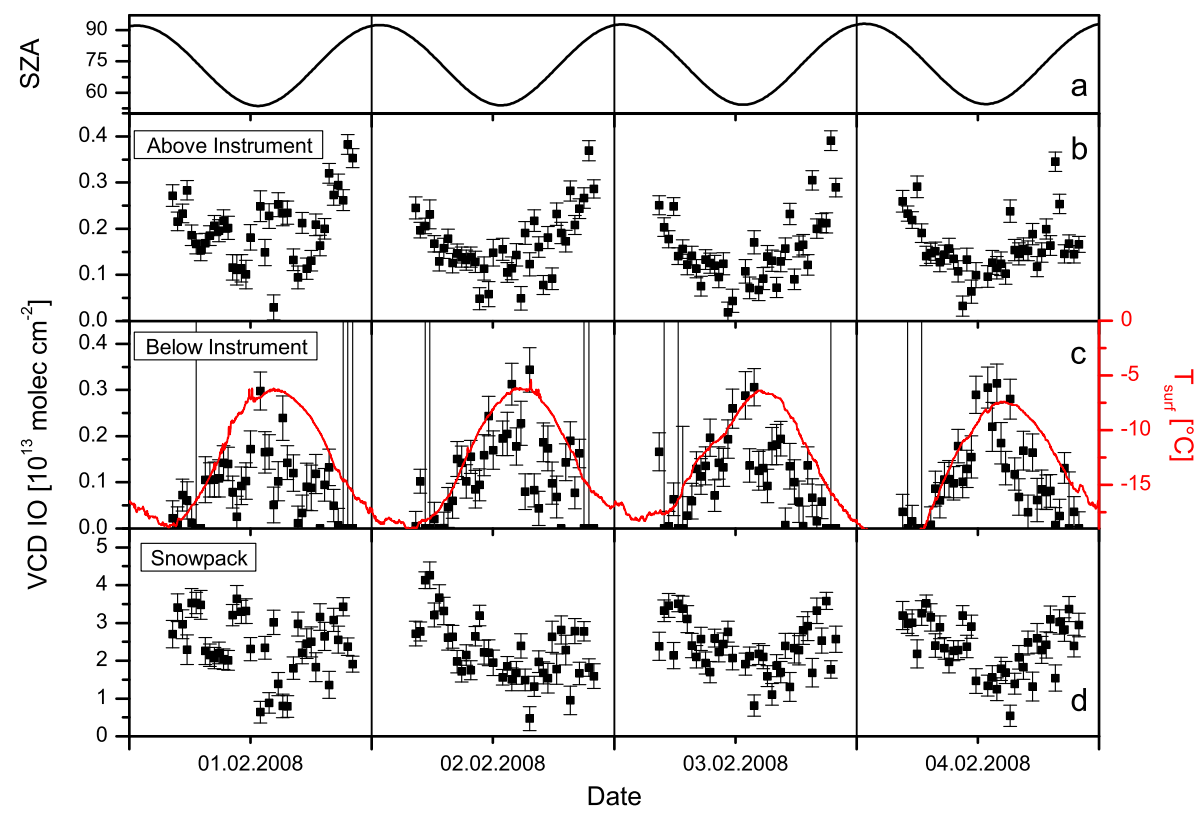

Fig. 10. Retrieved partial IO VCDs above (b) and below (c) the instrument as well as inside the snowpack (d) during a four days period of clear sky in early February 2008. Surface temperature retrieved from the routine pyrradiometer measurements at Neumayer is shown in red. Panel a shows the SZA. Note the different axis scales for atmospheric and snowpack VCDs.

of IO is limited by self reaction, producing (instable) $\mathrm{I}_{2} \mathrm{O}_{2}$ and OIO. The latter has not been detected by the MAXDOAS instrument at Neumayer, and recent studies indicate that its photochemical lifetime is very short (Gómez Martín et al., 2009). The photolysis of OIO yields I atoms. Giving $\mathrm{IO}$ mixing ratios of several ppb, the $\mathrm{I}+\mathrm{O}_{3}$ reaction should lead to a very rapid destruction of ozone in the snow interstitial air, inhibiting a re-formation of $\mathrm{IO}$ via $\mathrm{I}+\mathrm{O}_{3}$. Given rate constants of $4.4 \times 10^{-11} \mathrm{~cm}^{3} \mathrm{molec}^{-1} \mathrm{~s}^{-1}$ and $5.2 \times$ $10^{-11} \mathrm{~cm}^{3} \mathrm{molec}^{-1} \mathrm{~s}^{-1}$ for Reactions (R5) and (R6), respectively, the lifetime of IO would be less than $0.01 \mathrm{~s}$, and high amounts of IO can only be sustained by fast recycling processes. Possibly, $\mathrm{I}_{2} \mathrm{O}_{2}$ decomposes quickly to IO by thermolysis (Vogt et al., 1999; Gómez Martín and Plane, 2009), and OIO can be converted to IO via reaction with NO (Pechtl et al., 2006; Plane et al., 2006), which is present in the snow pack at mixing ratios of up to $20 \mathrm{ppt}$. However, the high amounts of IO in the gas phase observed at Neumayer Station can most likely only be sustained by heterogeneous reactions on the snow surface. In general, iodine recycling of intermediate iodine reservoir species $\left(\mathrm{HOI}, \mathrm{INO}_{2}, \mathrm{INO}_{3}\right.$ and $\left.\mathrm{I}_{2} \mathrm{O}_{2}\right)$ at the snow surface, proceeding via aqueous phase reaction with iodide, can produce $I_{2}$ which is released back to the gas phase (for a comprehensive summary of these reaction cycles, see Zingler and Platt, 2005). Heterogeneous recycling mechanisms leading to the direct conversion of OIO to IO are, however, not known. A possible mechanism proposed by Saiz-Lopez et al. (2008) is production of higher iodine oxides by OIO and a subsequent photolysis of $\mathrm{I}_{\mathrm{x}} \mathrm{O}_{\mathrm{y}}$.

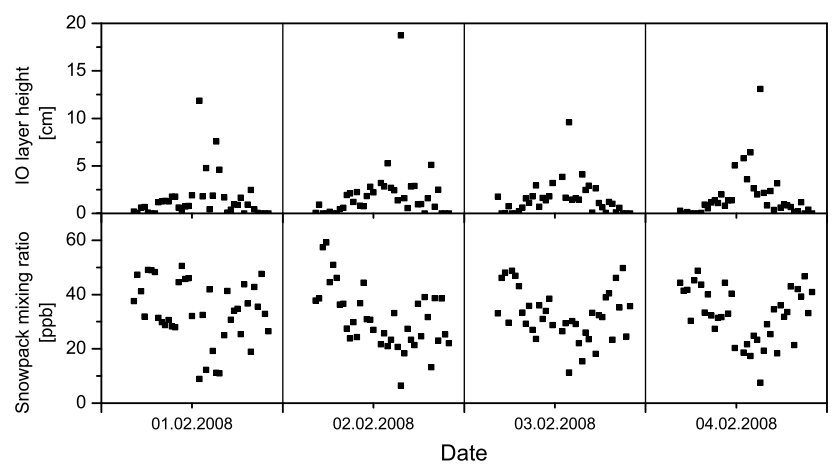

Fig. 11. Lower panel: estimated IO mixing ratios at the snow surface under the assumption of a constant IO concentration in the upper $25 \mathrm{~cm}$ of the snowpack. Upper panel: estimated IO layer height if the concentration in the atmosphere above the snow is equal to the snowpack concentration.

The retrieved IO partial VCDs in the atmosphere between the snow surface and the instrument (panel c of Fig. 10) are characterised by a distinct diurnal variation with a maximum of about $3 \times 10^{12} \mathrm{molec} / \mathrm{cm}^{2}$ around noon. Distributed only over a height of $7 \mathrm{~m}$, this corresponds to much higher concentrations than above the instrument, and it is likely that the majority of IO is located directly above the snow surface, as predicted by photochemical model calculations (Saiz-Lopez et al., 2008). Under the assumption 


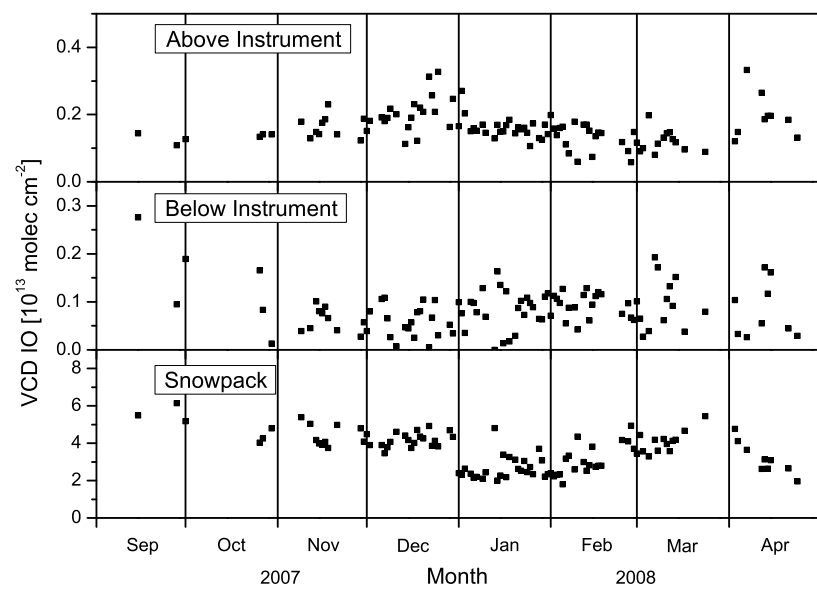

Fig. 12. Daily averaged clear-sky partial IO VCDs from spring 2007 to autumn 2008.

that atmospheric and snowpack IO concentrations are equal at the snow/atmosphere interface, an estimate for the IO layer height above the snowpack is calculated by dividing the partial VCD below the instrument (panel c of Fig. 10) by the snowpack IO concentration (lower panel of Fig. 11). The resulting IO layer height shown in the upper panel of Fig. 11 amounts to only a few centimetres. Similar layer heights and snowpack/atmosphere gradients have been found for $\mathrm{NO}_{\mathrm{x}}$ in the sunlit snow/atmosphere interface at Summit/Greenland (Dominé and Shepson, 2002). Furthermore, a very strong gradient between snowpack and atmosphere has been observed for organohalogens (methyl bromide, ethyland methyl iodide) at Summit (Swanson et al., 2002), with a layer of up to $3.5 \mathrm{ppt}$ of methyl iodide in the uppermost $10 \mathrm{~cm}$ of the snowpack and less than $0.3 \mathrm{ppt}$ in the air, strongly suggesting photochemical production mechanisms of these (and several other) compounds (Grannas et al., 2007).

The IO partial VCD below the instrument correlates well with the snow temperature (red line in Fig. 10) determined from the routine pyrradiometer measurements at Neumayer under the assumption that snow represents a black body (data available at http://www.awi.de/en/infrastructure/stations/ neumayer_station/observatories/meteorological_observatory/ radiation_measurements). Given an amplitude of the snow surface temperature of about $10 \mathrm{~K}$ between day and night, it is possible that small-scale convection due to heating of interstitial air in the uppermost snow layer causes a transport of iodine radicals from the snowpack into the atmosphere, whereas these transport processes are suppressed at high SZA owing to radiative cooling of the snow surface and a stable stratification of the boundary layer.

\subsection{Seasonal variation of IO}

Daily averaged partial IO VCDs are calculated including only clear-sky data as determined by the $\mathrm{O}_{4}$ measurements (see Sect. 3), and excluding retrievals which did not converge $\left(\chi_{R}^{2}>50\right.$, see Eq. 9). The resulting seasonal variation is shown in Fig. 12. No pronounced seasonal pattern of the partial IO VCDs above and below the instrument as well as in the snowpack is apparent, apart from a slight minimum of the IO amount inside the snowpack in late summer (January/February), and a decline in snowpack IO from mid March to April. In contrast to the MAX-DOAS IO observations, particulate iodine measured inside the snowpack (Fig. 9) shows a strong seasonality. Concentrations drop from up to $700 \mathrm{ng} / \mathrm{l}$ in winter down to almost zero in late summer, with a sharp gradient at the beginning and end of polar winter. This finding suggests that particulate iodine is quickly released to the gas phase as soon as sunlight is available.

Note that the MAX-DOAS measurements were only performed during the day $\left(\mathrm{SZA}<85^{\circ}\right)$, when a photochemical steady state between I and IO is already established (Vogt et al., 1999). Thus the IO VCDs averaged over $24 \mathrm{~h}$, and therefore the total amount of reactive iodine released from the snowpack, are likely to be smaller as the amount of sunlight is decreased in early spring and late autumn.

The partial VCD below the instrument shows a large scatter, likely because the sensitivity for the atmospheric layer below the instrument is very sensitive to perturbations of the light path by blowing snow, which can already occur at wind speeds of about $5 \mathrm{~m} / \mathrm{s}$. In case of blowing snow, the variation of the IO dSCDs with elevation angle will be reduced for the downward viewing angles, and the retrieval will attribute at least parts of the IO column above the snow surface to the snowpack.

Unfortunately, there is only a limited number of clear-sky observations in September and October 2007, and no elevated $\mathrm{BrO}$ in the boundary layer is observed by the UV spectrometer from mid September on. Therefore no conclusions on possible interactions between bromine and iodine chemistry in polar spring can be drawn on the basis of the existing data, although somewhat higher IO partial VCDs below the instrument and inside the snowpack are retrieved in September 2007.

The IO SCDs estimated from the MAX-DOAS measurements at Neumayer and from our previous zenith-sky measurements at Neumayer (Frieß et al., 2001) are of the same order of magnitude (around $\left.(2-10) \times 10^{13} \mathrm{molec} / \mathrm{cm}^{2}\right)$. In Frieß et al. (2001), the seasonal variation of the IO dSCD, i.e. the difference between $\mathrm{SZA}=80^{\circ}$ and $92^{\circ}$ was presented, showing a decrease in summer. Using a fixed Fraunhofer reference spectrum (instead of a daily reference), it turned out later that this is feature is caused by a slower decrease of the IO SCD during twilight in summer than in autumn and spring. From our initial zenith-sky measurements at 
Neumayer (Frieß et al., 2001), we were only able to speculate about the vertical profile of IO, and mixing ratios were estimated under the assumption of a constant IO concentration within the boundary layer. From our MAX-DOAS measurements presented here, it turned out that this assumption is not valid but that the majority of IO is located inside the snowpack.

From the longpath-DOAS measurements at Halley by Saiz-Lopez et al. (2007a), $24 \mathrm{~h}$ averages of the IO mixing ratio are reported. These decrease as days become shorter since there is no IO during the night. In contrast, daily averages calculated from our MAX-DOAS measurements are representative only for daytime $\left(\mathrm{SZA}<85^{\circ}\right)$, leading to a much smaller seasonal variation. Furthermore, the MAXDOAS data during early spring and late autumn are very sparse due to the short duration of solar illumination and unfavourable weather conditions, decreasing the number of valid data points flagged as clear-sky for these periods.

\section{Conclusions}

The MAX-DOAS measurements of iodine monoxide, together with total iodine measurements from snow pits at Neumayer Station, Antarctica, suggest that the snowpack represents a strong source for iodine radicals in the boundary layer of coastal Antarctica. By including viewing directions not only pointing to the sky, but also downwards on the snow pack, the MAX-DOAS measurements can only be explained by the presence of huge amounts of IO in the snowpack interstitial air.

Using a retrieval algorithm on the basis of a coupled air/snowpack Monte Carlo radiative transfer model, snowpack IO concentrations can only be roughly estimated since the optical properties of the snowpack are not well known (and are likely to change with season), and the results strongly depend on assumptions on the depth of the IO layer inside the snowpack. Retrieved IO mixing mixing ratios in the range of $50 \mathrm{ppb}$ inside the snowpack are therefore subject to large uncertainties, and represent only an estimate of the order of magnitude. IO partial VCDs above the snowpack (between snow surface and instrument) are about a factor of 10 smaller than inside the snowpack, and air highly enriched in IO is likely to be present only in a very thin layer of several centimetres height above the snow surface.

Total particulate iodine inside the snowpack shows a strong seasonal cycle, with maximum values of up to $650 \mathrm{ng} / \mathrm{l}$ in mid winter. Particulate iodine concentrations rapidly decrease as soon as sunlight is available during polar summer, indicating a photochemically driven conversion to gaseous iodine compounds. The particulate iodine accumulated during winter corresponds to about $95 \mathrm{ppb}$ of iodine in the gas phase, and thus represents a sufficient reservoir for the observed IO concentrations in the snow interstitial.
The primary sources for the observed iodine enrichment are likely to be biogenic processes in the ocean, but possibly also at the bottom of the sea ice which is a habitat for various algae species which are potentially emitting iodocarbons. However, it still remains unclear how the strong accumulation of iodine on the snowpack occurs. Furthermore, it can only be speculated about the transport pathways of shortlived iodine compounds from the coast to inland Antarctica, observed both from satellite (Schönhardt et al., 2008) and on meteorites as well as snow- and rock samples (Heumann et al., 1987). Apart from the transport of $\mathrm{CH}_{3} \mathrm{I}$, with a photochemical lifetime of several days, to the Antarctic continent, one might speculate if a cycle of emission and re-deposition of iodine compounds from/to the snowpack, e.g. as ultrafine particles, represents a transport pathway in a kind of "hopping process".

The presence IO concentrations in the ppb range cannot be explained on the basis of our current knowledge of iodine chemistry, which predicts that IO concentrations should be limited by self reaction. The production of OIO should result in IO lifetimes of less than $0.01 \mathrm{~s}$. Rapid destruction of ozone by the $\mathrm{I}+\mathrm{O}_{3}$ reaction should inhibit the re-formation of IO. It can only be speculated how such high IO amounts can be sustained: (1) the yield of OIO production is much smaller than currently estimated; (2) higher iodine oxides, which might have a short photolytic lifetime, are quickly produced by OIO polymerisation; (3) there are unknown heterogeneous reactions on snow surfaces, leading to a fast re-conversion of OIO to IO.

IO present at these extraordinarily high concentrations in the snowpack interstitial air and in the atmosphere near the surface of the Antarctic shelf ice at Neumayer Station is expected to have a significant, if not dominating impact on photochemistry. Ozone is expected to be completely destroyed inside the snowpack by catalytic cycles involving iodine radicals. The same should be the case for the lowermost atmospheric layers in contact with the snowpack, although vertical mixing might lead to dilution effects by transport of ozonerich air from above (Saiz-Lopez et al., 2008). The formation of higher iodine oxides is likely to lead to the production of ultrafine particles. These are possibly scavenged by the snow matrix. Possible heterogeneous mechanisms leading to a recycling of reactive iodine from higher iodine oxides are yet unknown and require further field and laboratory studies. Finally, the interaction of $\mathrm{BrO}$ and $\mathrm{IO}$ photochemical cycles via reaction of $\mathrm{BrO}+\mathrm{IO}$ to $\mathrm{Br}+\mathrm{OIO}$ is expected to lead to an amplification of ozone destruction during $\mathrm{BrO}$ explosion events in polar spring (Vogt et al., 1999). 
Acknowledgements. This work has been financially supported by the German Research Association (DFG, project FR2497/2-1). Hans Oerter and Gert König-Langlo from AWI are gratefully acknowledged for providing the snow pit oxygen isotope data and meteorological data, respectively. Many thanks to the Neumayer over-winterer crews for operating and maintaining the long-term measurements at Neumayer for more than 10 years. Michel van Roozendael and Caroline Fayt from BIRA are gratefully acknowledged for providing the Windoas analysis program.

Edited by: M. Ammann

\section{References}

Aldahan, A., Persson, S., Possnert, G., and Hou, X. L.: Distribution of ${ }^{127}$ I and ${ }^{129} \mathrm{I}$ in precipitation at high European latitudes, Geophys. Res. Lett., 36, L11805, doi:10.1029/2009GL037363, 2009.

Alicke, B., Hebestreit, K., Stutz, J., and Platt, U.: Iodine oxide in the marine boundary layer, Nature, 397, 572-573, doi:10.1038/ 17508, 1999.

Allan, B. J., McFiggans, G., and Plane, J. M. C.: Observation of iodine monoxide in the remote marine boundary layer, J. Geophys. Res., 105, 14363-14369, doi:10.1029/1999JD901188, 2000.

Bloss, W. J., Rowley, D. M., Cox, R. A., and Jones, R. L.: Kinetics and Products of the IO Self-Reaction, J. Phys. Chem., 105, 78407854, doi:10.1021/jp0044936, 2001.

Bogumil, K., Orphal, J., and Burrows, J. P.: Temperature-dependent absorption cross-sections of $\mathrm{O}_{3}, \mathrm{NO}_{2}$, and other atmospheric trace gases measured with the SCIAMACHY spectrometer, in: Proceedings of the ERS-Envisat Symposium, Gothenburg, Sweden, 2000.

Bruns, M., Buehler, S., Burrows, J., Heue, K., Platt, U., Pundt, I., Richter, A., Rozanov, A., Wagner, T., and Wang, P.: Retrieval of profile information from airborne multiaxis UV-visible skylight absorption measurements, Appl. Opt., 43, 4415-4426, doi:10. 1364/AO.43.004415, 2004.

Carpenter, L. J.: Iodine in the Marine Boundary Layer, Chemical Reviews, 103, 4953-4962, doi:10.1021/cr0206465, 2003.

Carpenter, L. J., Sturges, W. T., Penkett, S. A., Liss, P., Alicke, B., Hebestreit, K., and Platt, U.: Short-lived alkyl iodides and bromides at Mace Head, Ireland: links to biogenic sources and halogen oxide production, J. Geophys. Res., 104, 1679-1689, doi:10.1029/98JD02746, 1999.

Chance, K. and Spurr, R. J. D.: Ring effect studies; Rayleigh scattering, including molecular parameters for rotational Raman scattering and the Fraunhofer spectrum, Appl. Optics, 36, 52245230, 1997.

Cox, R. A., Bloss, W. J., and Jones, R. L.: OIO and the atmospheric cycle of iodine, Geophys. Res. Lett., 26, 1857-1860, doi: 10.1029/1999GL900439, 1999.

Deutschmann, T.: Atmospheric radiative transfer modelling using Monte Carlo methods, Diploma thesis, University of Heidelberg, 2008.

Dominé, F. and Shepson, P. B.: Air-Snow Interactions and Atmospheric Chemistry, Science, 297, 1506-1510, doi:10.1126/ science.1074610, 2002.

Dreibus, G. and Wänke, H.: Halogens in Antarctic Meteorites, Meteoritics, 18, 291-292, 1983.
Dreibus, G., Spettel, B., and Wänke, H.: Halogens in meteorites and their primordial abundances, in: Origin and Distribution of the Elements, edited by L. H. Ahrens, 33-38, 1979.

Fayt, C. and van Roozendael, M.: Windoas user manual, IASBBIRA, Brussels, Belgium, 2001.

Ferlemann, F., Bauer, N., Fitzenberger, R., Harder, H., Osterkamp, H., Perner, D., Platt, U., Schneider, M., Vradelis, P., and Pfeilsticker, K.: Differential optical absorption spectroscopy instrument for stratospheric ballonborne trace-gas studies, Appl. Optics, 39, 2377-2386, 2000.

Frieß, U., Wagner, T., Pundt, I., Pfeilsticker, K., and Platt, U.: Spectroscopic Measurements of Tropospheric Iodine Oxide at Neumayer Station, Antarctica, Geophys. Res. Lett., 28, 1941-1944, doi:10.1029/2000GL012784, 2001.

Frieß, U., Hollwedel, J., König-Langlo, G., Wagner, T., and Platt, U.: Dynamics and chemistry of tropospheric bromine explosion events in the Antarctic coastal region, J. Geophys. Res., 109, D06305, doi:10.1029/2003JD004133, 2004.

Frieß, U., Monks, P., Remedios, J., Rozanov, A., Sinreich, R., Wagner, T., and Platt, U.: MAX-DOAS $\mathrm{O}_{4}$ measurements: A new technique to derive information on atmospheric aerosols: 2 . Modeling studies, J. Geophys. Res., 111, D14203, doi:10.1029/ 2005JD006618, 2006.

Frost, G. J., Goss, L. M., and Vaida, V.: Measurements of highresolution ultraviolet-visible absorption cross sections at stratospheric temperatures 2. Chlorine dioxide, J. Geophys. Res., 101, 3879-3884, doi:10.1029/95JD03389, 1995.

Garland, J. A., Elzerman, A. W., and Penkett, S. A.: The Mechanism for Dry Deposition of Ozone to Seawater Surfaces, J. Geophys. Res., 85, 7488-7492, doi:10.1029/JC085iC12p07488, 1980.

Gilfedder, B. S., Petri, M., and Biester, H.: Iodine speciation in rain and snow: Implications for the atmospheric iodine sink, J. Geophys. Res., 112, D07301, doi:10.1029/2006JD007356, 2007a.

Gilfedder, B. S., Petri, M., and Biester, H.: Iodine and bromine speciation in snow and the effect of orographically induced precipitation, Atmos. Chem. Phys., 7, 2661-2669, 2007b, http://www.atmos-chem-phys.net/7/2661/2007/.

Gilfedder, B. S., Lai, S. C., Petri, M., Biester, H., and Hoffmann, T.: Iodine speciation in rain, snow and aerosols, Atmos. Chem. Phys., 8, 6069-6084, 2008, http://www.atmos-chem-phys.net/8/6069/2008/.

Göktas, F.: Characterisation of glacio-chemical and glaciometeorological parameters of Amundsenisen, Dronning Maud Land, Antarctica, Reports on polar and marine research, 425, 1170, 2002.

Göktas, F., Fischer, H., Oerter, H., Weller, R., Sommer, S., and Miller, H.: A glacio-chemical characterization of the new EPICA deep-drilling site on Amundsenisen, Dronning Maud Land, Antarctica, Annals of Glaciology, 35, 347-354, doi:10. 3189/172756402781816474, 2002.

Gómez Martín, J. C. and Plane, J. M.: Determination of the OIO bond dissociation energy by photofragment excitation spectroscopy, Chem. Phys. Lett., 474, 79-83, 2009.

Gómez Martín, J. C., Ashworth, S. H., Mahajan, A. S., and Plane, J. M. C.: Photochemistry of OIO: Laboratory study and atmospheric implications, Geophys. Res. Lett., 36, L09802, doi: 10.1029/2009GL037642, 2009.

Grainger, J. F. and Ring, J.: Anomalous Fraunhofer line profiles, 
Nature, 193, p. 762, 1962.

Grannas, A. M., Jones, A. E., Dibb, J., Ammann, M., Anastasio, C., Beine, H. J., Bergin, M., Bottenheim, J., Boxe, C. S., Carver, G., Chen, G., Crawford, J. H., Domin, F., Frey, M. M., Guzmn, M. I., Heard, D. E., Helmig, D., Hoffmann, M. R., Honrath, R. E., Huey, L. G., Hutterli, M., Jacobi, H. W., Kln, P., Lefer, B., McConnell, J., Plane, J., Sander, R., Savarino, J., Shepson, P. B., Simpson, W. R., Sodeau, J. R., von Glasow, R., Weller, R., Wolff, E. W., and Zhu, T.: An overview of snow photochemistry: evidence, mechanisms and impacts, Atmos. Chem. Phys., 7, 4329-4373, 2007,

http://www.atmos-chem-phys.net/7/4329/2007/.

Grenfell, T. C., Warren, S. G., and Mullen, P. C.: Reflection of solar radiation by the Antarctic snow surface at ultraviolet, visible, and near-infrared wavelengths, J. Geophys. Res., 99, 18669-18684, doi:10.1029/94JD01484, 1994.

Helsen, M. M., van de Wal, R., van den Broeke, M., van As, D., Meijer, H., and Reijmer, C.: Oxygen isotope variability in snow from western Dronning Maud Land, Antarctica and its relation to temperature, Tellus B, 57, 423-435, doi:10.1111/j.1600-0889. 2005.00162.x, 2005.

Hendrick, F., Van Roozendael, M., Chipperfield, M. P., Dorf, M., Goutail, F., Yang, X., Fayt, C., Hermans, C., Pfeilsticker, K., Pommereau, J.-P., Pyle, J. A., Theys, N., and De Mazire, M.: Retrieval of stratospheric and tropospheric $\mathrm{BrO}$ profiles and columns using ground-based zenith-sky DOAS observations at Harestua, 60 N, Atmos. Chem. Phys., 7, 4869-4885, 2007, http://www.atmos-chem-phys.net/7/4869/2007/.

Henyey, L. C. and Greenstein, J. L.: Diffuse radiation in the Galaxy, Astrophys. J., 93, 70-83, 1941.

Hermans, C., Vandaele, A. C., Fally, S., Carleer, M., Colin, R., Coquart, B., Jenouvrier, A., and Mérienne, M. F.: Absorption crosssection of the collision-induced bands of oxygen from the UV to the NIR, in: NATO Advanced Research Workshop: Weakly Interacting Molecular Pairs: Unconventional Absorbers of Radiation in the Atmosphere, St. Petersburg, Russia, 2002.

Heumann, K., Gall, M., and H., W.: Geochemical investigations to explain iodine-overabundances in Antarctic meteorites, Geochim. Cosmochim. Acta, 51, 2541-2547, doi:10. 1016/0016-7037(87)90304-8, 1987.

Hönninger, G.: Referenzspektren reaktiver Halogenverbindungen für DOAS-Messungen, Diploma thesis, University of Heidelberg, in German, 1999.

Hónninger, G., von Friedeburg, C., and Platt, U.: Multi axis differential optical absorption spectroscopy (MAX-DOAS), Atmos. Chem. Phys., 4, 231-254, 2004, http://www.atmos-chem-phys.net/4/231/2004/.

Hur, S. D., Cunde, X., Hong, S., Barbante, C., Gabrielli, P., Lee, K., Boutron, C. F., and Ming, Y.: Seasonal patterns of heavy metal deposition to the snow on Lambert Glacier basin, East Antarctica, Atmos. Env., 41, 8567-8578, doi:10.1016/j.atmosenv.2007. 07.012, 2007.

Jacobi, H. W., Weller, R., Jones, A. E., Anderson, P. S., and Schrems, O.: Peroxyacetyl nitrate (PAN) concentrations in the Antarctic troposphere measured during the photochemical experiment at Neumayer (PEAN'99), Atmos. Env., 34, 5235-5247, doi:10.1016/S1352-2310(00)00190-4, 2000.

Jones, A. E., Weller, R., Minikin, A., Wolff, E. W., Sturges, W. T., McIntyre, H. P., Leonard, S. R., Schrems, O., and Bauguitte,
S.: Oxidized nitrogen chemistry and speciation in the Antarctic troposphere, J. Geophys. Res., 104, 21355-21366, doi:10.1029/ 1999JD900362, 1999.

Jones, A. E., Weller, R., Anderson, P. S., Jacobi, H. W., Wolff, E. W., Schrems, O., and Miller, H.: Measurements of $\mathrm{NO}_{\mathrm{x}}$ Emissions from the Antarctic Snowpack, Geophys. Res. Lett., 28, 1499-1502, doi:10.1029/2000GL011956, 2001.

King, M. D. and Simpson, W. R.: Extinction of UV radiation in Arctic snow at Alert, Canada $\left(82^{\circ} \mathrm{N}\right)$, J. Geophys. Res., 106, 12499-12507, doi:10.1029/2001JD900006, 2001.

Kurucz, R. L., Furenlid, I., Brault, J., and Testerman, L.: Solar flux atlas from 296 to $1300 \mathrm{~nm}$, Tech. rep., National Solar Observatory, 1984.

Langenauer, M. and Krähenbühl, U.: Depth-profiles and surface enrichment of the halogens in four Antarctic H5 chondrites and in two non-Antarctic chondrites, Meteoritics, 28, 98-104, 1993.

Lee-Taylor, J. and Madronich, S.: Calculation of actinic fluxes with a coupled atmosphere - snow radiative transfer model, J. Geophys. Res., 107, 4796, doi:10.1029/2002JD002084, 2002.

Marquard, L. C., Wagner, T., and Platt, U.: Improved air mass factor concepts for scattered radiation differential optical absorption spectroscopy of atmospheric species, J. Geophys. Res., 105, 1315-1327, doi:10.1029/1999JD900340, 2000.

Marshak, A. and Davis, A.: 3D Radiative Transfer in Cloudy Atmospheres, Springer, 2005.

Martino, M., Mills, G. P., Woeltjen, J., and Liss, P. S.: A new source of volatile organoiodine compounds in surface seawater, Geophys. Res. Lett., 36, L01609, doi:10.1029/2008GL036334, 2009.

McFiggans, G., Plane, J. M. C., Allan, B. J., and Carpenter, L. J.: A modeling study of iodine chemistry in the marine boundary layer, J. Geophys. Res., 105, 14371-14385, doi:10.1029/ 1999JD901187, 2000.

Moran, J. E., Oktay, S., Santschi, P. H., and Schink, D. R.: Atmospheric Dispersal of 129Iodine from Nuclear Fuel Reprocessing Facilities, Env. Sci. Tech., 33, 2536-2542, doi:10.1021/ es9900050, 1999.

O'Dowd, C. and Hoffmann, T.: Coastal New Particle Formation: A Review of the Current State-Of-The-Art, Environ. Chem., 3, 245-255, doi:10.1071/EN05077, 2006.

Oerter, H., Graf, W., Meyer, H., and Wilhelms, F.: The EPICA ice core from Dronning Maud Land: first results from stableisotope measurements, Ann. Glaciol., 39, 307-312, doi:10.3189/ $172756404781814032,2004$.

Pechtl, S., Lovejoy, E. R., Burkholder, J. B., and von Glasow, R.: Modeling the possible role of iodine oxides in atmospheric new particle formation, Atmos. Chem. Phys., 6, 505-523, 2006, http://www.atmos-chem-phys.net/6/505/2006/.

Plane, J. M. C., Joseph, D. M., Allan, B. J., Ashworth, S. H., and Francisco, J. S.: An Experimental and Theoretical Study of the Reactions $\mathrm{OIO}+\mathrm{NO}$ and $\mathrm{OIO}+\mathrm{OH}$, J. Phys. Chem., 110, 93100, doi:10.1021/jp055364y, 2006.

Platt, U.: Differential optical absorption spectroscopy (DOAS), in: Air Monitoring by Spectroscopic Techniques, vol. 127, John Wiley \& Sons, Inc., 1994.

Platt, U. and Stutz, J.: Differential optical absorption spectroscopy, Springer Verlag, 2008.

Rodgers, C. D.: Inverse methods for atmospheric sounding, theory and practice, Series on Atmospheric, Oceanic and Planetary Physics, World Scientific, 2000. 
Rothman, L. S., Rinsland, C. P., Goldman, A., Massie, S. T., Edwards, D. P., Flaud, J.-m., Perrin, A., Camy-peyret, C., Dana, V., Mandin, J. Y., Schroeder, J., Mccann, A., Gamache, R. R., Wattson, R. B., Yoshino, K., Chance, K. V., Jucks, K. W., Brown, L. R., Nemtchinov, V., and Varanasi, P.: The HITRAN Molecular Spectroscopic Database And HAWKS (HITRAN Atmospheric Workstation): 1996 Edition, J. Quant. Spec. Rad. Trans., 60, 665-710, doi:10.1016/S0022-4073(98)00078-8, 1998.

Saiz-Lopez, A., Chance, K., Liu, X., Kurosu, T. P., and Sander, S. P.: First observations of iodine oxide from space, Geophys. Res. Lett., 34, L12812, doi:10.1029/2007GL030111, 2007a.

Saiz-Lopez, A., Mahajan, A., Salmon, R., Bauguitte, S., Jones, A., Roscoe, H., and Plane, J.: Boundary layer halogens in coastal Antarctica, Science, 317, 348-351, 2007b.

Saiz-Lopez, A., Plane, J. M. C., Mahajan, A. S., Anderson, P. S., Bauguitte, S. J.-B., Jones, A. E., Roscoe, H. K., Salmon, R. A., Bloss, W. J., Lee, J. D., and Heard, D. E.: On the vertical distribution of boundary layer halogens over coastal Antarctica: implications for $\mathrm{O}_{3}, \mathrm{HO}_{\mathrm{x}}, \mathrm{NO}_{\mathrm{x}}$ and the $\mathrm{Hg}$ lifetime, Atmos. Chem. Phys., 8, 887-900, 2008,

http://www.atmos-chem-phys.net/8/887/2008/.

Savarino, J., Kaiser, J., Morin, S., Sigman, D. M., and Thiemens, M. H.: Nitrogen and oxygen isotopic constraints on the origin of atmospheric nitrate in coastal Antarctica, Atmos. Chem. Phys., 7, 1925-1945, 2007,

http://www.atmos-chem-phys.net/7/1925/2007/.

Schönhardt, A., Richter, A., Wittrock, F., Kirk, H., Oetjen, H., Roscoe, H. K., and Burrows, J. P.: Observations of iodine monoxide columns from satellite, Atmos. Chem. Phys., 8, 637653, 2008,

http://www.atmos-chem-phys.net/8/637/2008/.

Sinreich, R., Frieß U., and Platt, U.: Multi axis differential optical absorption spectroscopy (MAX-DOAS) of gas and aerosol distributions, Faraday Discuss., 130, 153-164, doi:10.1039/ b419274p, 2005.

Solomon, S., Garcia, R. R., and Ravishankara, A. R.: On the role of iodine in ozone depletion, J. Geophys. Res., 99, 20491-20499, doi:10.1029/94JD02028, 1994.

Swanson, A. L., Blake, N. J., Dibb, J. E., Albert, M. R., Blake, D. R., and Sherwood Rowland, F.: Photochemically induced production of $\mathrm{CH}_{3} \mathrm{Br}, \mathrm{CH}_{3} \mathrm{I}, \mathrm{C}_{2} \mathrm{H}_{5} \mathrm{I}$, ethene, and propene within surface snow at Summit, Greenland, Atmos. Env., 36, 2671-2682, doi:10.1016/S1352-2310(02)00127-9, 2002.

Thompson, A. M. and Zafiriou, O. C.: Air-Sea Fluxes of Transient Atmospheric Species, J. Geophys. Res., 88, 6696-6708, doi:10. 1029/JC088iC11p06696, 1983.

Tucceri, M., Hölscher, D., Rodriguez, A., Dillon, T., and Crowley, J.: Absorption cross section and photolysis of OIO, Phys. Chem. Chem. Phys., 8, 834-846, doi:10.1039/b512702e, 2006.

Tuncel, G., Aras, N., and Zoller, W.: Temporal variations and sources of eiements in ihe South Pole atmosphere. 1. Nonenriched and moderately enriched elements, J. Geophys. Res., 94, 13025-13038, 1989.
Vandaele, A. C., Hermans, C., Simon, P. C., Carleer, M., Colin, R., Fally, S., Mérienne, M. F., Jenouvrier, A., and Coquart, B.: Measurements of the $\mathrm{NO}_{2}$ absorption cross-section from 42,000 $\mathrm{cm}^{-1}$ to $10,000 \mathrm{~cm}^{-1}(238-1000 \mathrm{~nm})$ at $220 \mathrm{~K}$ and $294 \mathrm{~K}$., J. of Quant. Spectrosc. and Rad. Transfer, 59, 171-184, doi:10.1016/ S0022-4073(97)00168-4, 1998.

Vogt, R., Sander, R., von Glasow, R., and Crutzen, P. J.: Iodine Chemistry and its Role in Halogen Activation and Ozone Loss in the Marine Boundary Layer: A Model Study, J. Atmos. Chem., 32, 375-395, doi:10.1023/A:1006179901037, 1999.

von Glasow, R. and Crutzen, P. J.: Model study of multiphase DMS oxidation with a focus on halogens, Atmos. Chem. Phys., 4, 589608, 2004,

http://www.atmos-chem-phys.net/4/589/2004/.

Wagenbach, D., Legrand, M., Fischer, H., Pichlmayer, F., and Wolff, E. W.: Atmospheric near-surface nitrate at coastal Antarctic sites, J. Geophys. Res., 103, 11007-11020, doi:10.1029/ 97JD03364, 1998.

Wagner, T., Dix, B., von Friedeburg, C., Frieß, U., Sanghavi, S., Sinreich, R., and Platt, U.: MAX-DOAS $\mathrm{O}_{4}$ measurements: A new technique to derive information on atmospheric aerosols - principles and information content, J. Geophys. Res., 109, D22205, doi:10.1029/2004JD004904, 2004.

Wagner, T., Burrows, J. P., Deutschmann, T., Dix, B., von Friedeburg, C., Frieß, U., Hendrick, F., Heue, K.-P., Irie, H., Iwabuchi, H., Kanaya, Y., Keller, J., McLinden, C. A., Oetjen, H., Palazzi, E., Petritoli, A., Platt, U., Postylyakov, O., Pukite, J., Richter, A., van Roozendael, M., Rozanov, A., Rozanov, V., Sinreich, R., Sanghavi, S., and Wittrock, F.: Comparison of box-airmass-factors and radiances for Multiple-Axis Differential Optical Absorption Spectroscopy (MAX-DOAS) geometries calculated from different UV/visible radiative transfer models, Atmos. Chem. Phys., 7, 1809-1833, 2007,

http://www.atmos-chem-phys.net/7/1809/2007/.

Warren, S. G.: Optical Properties of Snow, Rev. Geophys., 20, 6789, doi:10.1029/RG020i001p00067, 1982.

Weller, R., Traufetter, F., Fischer, H., Oerter, H., Piel, C., and Miller, H.: Postdepositional losses of methane sulfonate, nitrate, and chloride at the European Project for Ice Coring in Antarctica deep-drilling site in Dronning Maud Land, Antarctica, J. Geophys. Res., 109, D07301, doi:10.1029/2003JD004189, 2004.

Wittrock, F., Müller, R., Richter, A., Bovensmann, H., and Burrows, J. P.: Measurements of iodine monoxide (IO) above Spitsbergen, Geophys. Res. Lett., 27, 1471-1474, doi:10.1029/ 1999GL011146, 2000.

Wittrock, F., Oetjen, H., Richter, A., Fietkau, S., Medeke, T., Rozanov, A., and Burrows, J. P.: MAX-DOAS measurements of atmospheric trace gases in Ny-Ålesund - Radiative transfer studies and their application, Atmos. Chem. Phys., 4, 955-966, 2004, http://www.atmos-chem-phys.net/4/955/2004/.

Zingler, J. and Platt, U.: Iodine oxide in the Dead Sea Valley: Evidence for inorganic sources of boundary layer IO, J. Geophys. Res., 110, D07307, doi:10.1029/2004JD004993, 2005. 